BNL-113231-2016-JA

\title{
Proton-Coupled Electron Transfer in a Strongly Coupled Photosystem II-Inspired Chromophore-Imidazole-Phenol Complex: Stepwise Oxidation and Concerted Reduction
}

\author{
Gerald F. Manbeck, Etsuko Fujita, and Javier J. Concepcion
}

Submitted to Journal of the American Chemical Society

September 2016

Chemistry Department

Brookhaven National Laboratory

\author{
U.S. Department of Energy \\ USDOE Office of Science (SC), \\ Basic Energy Sciences (BES) (SC-22)
}

Notice: This manuscript has been authored by employees of Brookhaven Science Associates, LLC under Contract No. DE- SC0012704 with the U.S. Department of Energy. The publisher by accepting the manuscript for publication acknowledges that the United States Government retains a non-exclusive, paid-up, irrevocable, world-wide license to publish or reproduce the published form of this manuscript, or allow others to do so, for United States Government purposes. 


\section{DISCLAIMER}

This report was prepared as an account of work sponsored by an agency of the United States Government. Neither the United States Government nor any agency thereof, nor any of their employees, nor any of their contractors, subcontractors, or their employees, makes any warranty, express or implied, or assumes any legal liability or responsibility for the accuracy, completeness, or any third party's use or the results of such use of any information, apparatus, product, or process disclosed, or represents that its use would not infringe privately owned rights. Reference herein to any specific commercial product, process, or service by trade name, trademark, manufacturer, or otherwise, does not necessarily constitute or imply its endorsement, recommendation, or favoring by the United States Government or any agency thereof or its contractors or subcontractors. The views and opinions of authors expressed herein do not necessarily state or reflect those of the United States Government or any agency thereof. 


\title{
Proton Coupled Electron Transfer in a Strongly Coupled Photosys- tem II-Inspired Chromophore-Imidazole-Phenol Complex: Stepwise Oxidation and Concerted Reduction
}

\author{
Gerald F. Manbeck,* Etsuko Fujita, and Javier J. Concepcion* \\ Chemistry Division, Brookhaven National Laboratory, Upton, NY 11973-5000, United States.
}

\author{
Supporting Information Placeholder
}

\begin{abstract}
Proton-coupled electron-transfer (PCET) reactions were studied in acetonitrile for a Photosystem II (PSII) inspired $\left[\mathrm{Ru}(\mathrm{bpy})_{2}\left(\text { phen-imidazole- } \mathrm{Ph}(\mathrm{OH})\left({ }^{t} \mathrm{Bu}\right)_{2}\right)\right]^{2+}$, in which $\mathrm{Ru}(\mathrm{III})$ generated by a flash-quench sequence oxidizes the appended phenol and the proton is transferred to the hydrogen bonded imidazole base. In contrast to related systems, the donor and acceptor are strongly coupled as indicated by the shift in the $\mathrm{Ru}^{\mathrm{III} / \mathrm{II}}$ couple upon phenol oxidation, and intramolecular oxidation of the phenol by Ru(III) is energetically favorable by both stepwise or concerted pathways. The phenol oxidation occurs via a stepwise ET-PT mechanism with $k_{\mathrm{ET}}=2.7 \times 10^{7} \mathrm{~s}^{-1}$ and a kinetic isotope effect (KIE) of $0.99 \pm 0.03$. The electron transfer reaction was characterized as adiabatic with $\lambda_{D A}=1.16 \mathrm{eV}$ and 280 $<H_{D A}<540 \mathrm{~cm}^{-1}$ consistent with strong electronic coupling and slow solvent dynamics. Reduction of the phenoxyl radical by the quencher radical was examined as the analogue of the redox reaction between the PSII tyrosyl radical and the oxygen evolving complex (OEC). In our PSII-inspired complex, the recombination reaction activation energy is $<2 \mathrm{kcal} \mathrm{mol}^{-1}$. The reaction is nonadiabatic $\left(V_{\mathrm{PCET}} \sim 22 \mathrm{~cm}^{-1}\right.$ (H) and $49 \mathrm{~cm}^{-1}$ (D)), concerted, and exhibits an unexpected inverse KIE of 0.55 that is attributed to greater overlap of the reactant vibronic ground state with the OD vibronic states of the proton acceptor due to the smaller quantum spacing of the deuterium vibrational levels.
\end{abstract}

\section{INTRODUCTION}

Faced with the exhaustibility of fossil fuel reserves and the rising level of atmospheric $\mathrm{CO}_{2}$ generated by their combustion, the need for renewable energy becomes more pressing. In principle, solar-driven production of liquid fuels (artificial photosynthesis) can be achieved by the multielectron, multiproton reduction of water to $\mathrm{H}_{2}$ and $\mathrm{CO}_{2}$ to $\mathrm{CO}, \mathrm{HCO}_{2} \mathrm{H}, \mathrm{CH}_{3} \mathrm{OH}, \mathrm{CH}_{4}$, and other oxygenates or hydrocarbons with water oxidation as the source of $\mathrm{H}^{+}$and electrons. A persistent challenge in artificial photosynthesis is the separation of charges with adequate energy to drive the pertinent redox reactions while suppressing the highly exergonic charge recombination. The recombination may occur on the ps timescale, ${ }^{1-4}$ while catalytic reactions such as the oxidation of water in Photosystem II (PSII) turn over more slowly (1-2 $\left.\mathrm{ms}^{-1}\right)$. $^{5,6}$

In PSII, ${ }^{7-11}$ charge separation by electron transfer (ET) from photoexcited ${ }^{*} \mathrm{P}_{680}$ to pheophytin to plastoquinone $\mathrm{Q}_{\mathrm{A}}$ ensues within a few hundred ps. ${ }^{8,9}$ The charge recombination from the $\left[\mathrm{P}_{680}{ }^{+} / \mathrm{Q}_{\mathrm{A}}{ }^{-}\right]$pair is highly exergonic but is sluggish (1-2 ms) due to its position in the Marcus inverted region. ${ }^{12-14}$ The strongly oxidizing $\mathrm{P}_{680}{ }^{+}$is reduced by tyrosine-161 $\left(\mathrm{Tyr}_{\mathrm{z}}\right)$ with multiphasic kinetics including a fast 20-40 ns component. ${ }^{15-18} \mathrm{The} \mathrm{Tyr}_{\mathrm{z}}$ oxidation $^{19-21}$ occurs by a multisite proton coupled electron transfer $(\mathrm{PCET})^{22-25}$ pathway $^{19}$ with proton transfer to the nearby His 190 residue $^{20}$ (2.5 $\AA \mathrm{O}-\mathrm{N}$ distance). ${ }^{21}$ In turn, the $\mathrm{Tyr}_{\mathrm{z}}$ radical is the oxidant in each oxidation step of the oxygen evolving complex with time constants from $\sim 30$ to $1400 \mu \mathrm{s}$. $6,10,11$

The photo-driven $\mathrm{Tyr}_{\mathrm{z}} / \mathrm{His}$ PCET chemistry of PSII has motivated the pursuit of synthetic mimics of this reaction (Chart 1) with tremendous variability in the mechanism based on structural and electronic considerations. In one subset of complexes, a high- potential chromophore excited state is capable of oxidizing an appended or freely diffusing phenol via PCET reductive quenching. ${ }^{26-30}$ The chromophore may function as the base and electron acceptor, i.e., Chart 1 complex $\mathrm{C},{ }^{26}$ or a dissolved base (including solvent and buffers) may function as the proton acceptor in a socalled multidirectional PCET. ${ }^{31,32}$

\section{Chart 1 Examples of Photo-Oxidation of Tyrosine-} Histidine Mimics

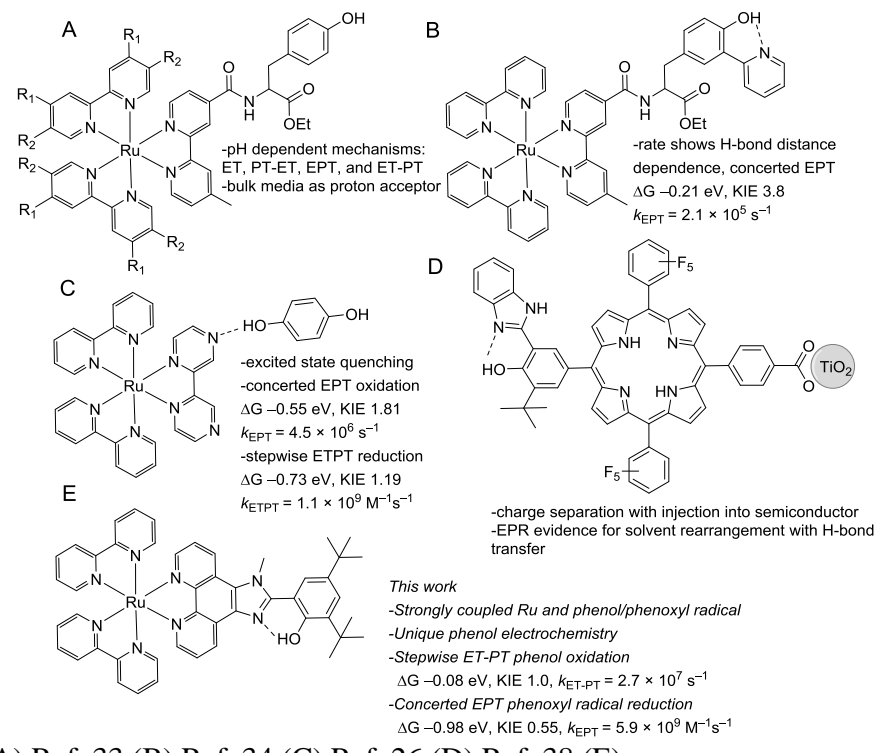

(A) Ref. 33 (B) Ref. 34 (C) Ref. 26 (D) Ref. 38 (E) 
In a second subset of tyrosine-histidine mimics, oxidation of the phenol to the phenoxyl radical is driven by a pre-oxidized chromophore generated through oxidative quenching of the excited state ${ }^{33-36}$ or charge injection into a semiconductor. ${ }^{37,38}$ Phenols with an internal H-bonded base, which are the most accurate representations of PSII, have been oxidized by appended polypyridyl $\mathrm{Ru}^{\text {III }}$ complexes (transiently in a flash-quench experiment) ${ }^{34}$, porphyrin radical cations, or excited porphyrin dyads. ${ }^{37-39}$ In recent contributions, the H-bond distance dependence of the rate constant was quantified in photochemical ${ }^{34}$ and chemical oxidation ${ }^{40}$ of H-bonded phenols with contrasting results between the two studies.

Precise determination of the mechanism of phenol oxidation is a persistent challenge in the field. Analysis is complicated because the PCET reaction is often poised to occur stepwise with electron transfer preceding proton transfer (ET-PT) or vice versa (PT-ET), or by a concerted mechanism (EPT) in which the electron and proton travel simultaneously at an energy minimum on the multi-dimensional potential energy surface which includes contributions from proton vibrational states, solvent reorganization, and the electron coordinate. The theory of PCET is well developed as an extension of semi-classical electron transfer theory that includes proton vibrational states in the donor and acceptor. ${ }^{41-46}$ The electron and proton movement can be discussed in terms of their adiabaticity. In this context, we will use "adiabatic" to describe an ET reaction that occurs on the electronic ground state due to strong coupling between the donor and acceptor and "nonadiabatic" to describe weak coupling between donor and acceptor diabatic states. In the nonadiabatic limit, electrons do not respond instantaneously to the solvent motion and electronic excited states are involved. Likewise, proton transfer may be described as vibrationally nonadiabatic or adiabatic depending upon the involvement of vibrational excited states. An excellent tutorial is available in the literature. ${ }^{43}$

For multisite PCET reactions, the EPT pathway is favorable energetically; however, it is often nonadiabatic and may be kinetically inhibited due to the requirement of simultaneous transfer of the electron and proton. Furthermore, a single system may exhibit four separate mechanisms depending on the solution medium. ${ }^{33}$ In water, the analysis is tedious due to the apparent $\mathrm{pH}$-dependent oxidation potential of the phenol which is an incorrect measure of driving force (the opposite of the standard free energy of the reaction). Correct analysis requires specification of the exact proton acceptor (i.e., water, buffer, or $\mathrm{OH}^{-}$) and its concentration. ${ }^{47,48}$ The thermochemistry of PCET models can be analyzed with a larger variation of chemical or electrochemically-supplied driving forces. ${ }^{40,49-53}$

The expansion of this field beyond intellectual analysis of PSII mimicry is evident in recent application-based studies employing H-bonded phenols as electron mediators. In one study, the quantum efficiency for photoelectrochemical water splitting with an iridium oxide water oxidation catalyst co-adsorbed onto $\mathrm{TiO}_{2}$ with a $\mathrm{Ru}(\mathrm{II})$ sensitizer was more than doubled by using a benzimidazole phenol mediator adsorbed on the catalyst to facilitate the slow electron transfer rate of the catalyst. ${ }^{54}$ In this system there was no covalent link between the mediator and sensitizer (nonadiabatic PCET) and complicated kinetics were observed.

It occurred to us that a spatially well-defined and strongly electronically coupled $\mathrm{Ru}$-phenol system could be useful in favoring an adiabatic mechanism and therefore facilitating a more rapid PCET process in application-based research. A literature search revealed intramolecular PCET in a Ru(II)-phenanthrolineimidazole-phenol complex, which should be strongly coupled, but the details of PCET were obscured because excited state quenching was rate limiting. ${ }^{36}$ Furthermore, the system contained an $\mathrm{NH}$ imidazole moiety which can also be oxidized via PCET pathways. $^{55}$

Here we report a study of the related complex Ru-phen-Im$\mathrm{PhOH}$ (Chart 1) which was inspired by the $\mathrm{Tyr}_{\mathrm{z}} / \mathrm{His}$ PCET process in PSII. Our system differs from PSII by direct connection of the imidazole and phenol to the chromophore through $\pi$ conjugation. The kinetics of phenol oxidation and phenoxyl radical reduction reactions are measured by transient absorption spectroscopy in acetonitrile to avoid proton transfer to the bulk solvent. It is important to note that the reduction reaction is often ignored in mimetic studies although it is the analogue of $\mathrm{Tyr}_{\mathrm{z}}{ }^{+}$reduction in PSII by the OEC, which takes place in micro to milliseconds. ${ }^{56,57}$ The phenoxyl reduction reaction is highly important in artificial photosynthetic systems using a phenol/base PCET mediator.

Our results show that the properties of $\mathrm{Ru}$-phen-Im- $\mathrm{PhOH}$ are atypical among other $\mathrm{Tyr}_{\mathrm{z}} / \mathrm{His}$ mimics. The photogenerated $\mathrm{Ru}^{\mathrm{III}}$ center is thermodynamically capable of oxidizing the phenol by concerted or stepwise pathways. Although the driving force for EPT is much larger, the ET-PT pathway (Scheme $1, \Delta G_{\mathrm{ET}}^{\mathrm{O}}=$ $-0.01 \mathrm{eV}$ ) is preferred with rate limiting ET of $\sim 3 \times 10^{7} \mathrm{~s}^{-1}$ at 20 ${ }^{\circ} \mathrm{C}$ and no kinetic isotope effect (KIE). A Marcus theory treatment of the kinetics reveals an adiabatic mechanism consistent with strong electronic coupling $\left(\lambda_{D A}=1.16 \mathrm{eV}\right.$ and $280<H_{D A}<540$ $\mathrm{cm}^{-1}$ ). The reduction of the phenoxyl radical by the methyl viologen radical cation $\left(\mathrm{MV}^{+\bullet}\right)$ is a concerted nonadiabatic $\left(\lambda_{D A}=1.7\right.$ $\mathrm{eV}, E_{\mathrm{a}}=1.4 \mathrm{kcal} \mathrm{mol}^{-1}$, and $V_{\text {PCET }} \sim 22 \mathrm{~cm}^{-1}$ ) multisite PCET reaction and exhibits a surprising inverse $\mathrm{KIE} k_{\mathrm{H}} / k_{\mathrm{D}}$ of $\sim 0.54$. The reaction is nearly activationless, and the unusual inverse KIE is possibly attributed to stronger overlap between the reactant vibronic ground state and product vibronic excited states for the deuterated complex due the smaller deuterium quantum spacing in phenol. Low frequency heavy atom vibrations are also suggested as promoting modes for the concerted reaction.

\section{Scheme 1. Intramolecular Proton Coupled Electron Trans- fer Following Flash Photolysis Showing Possible Stepwise and Concerted PCET Mechanisms}

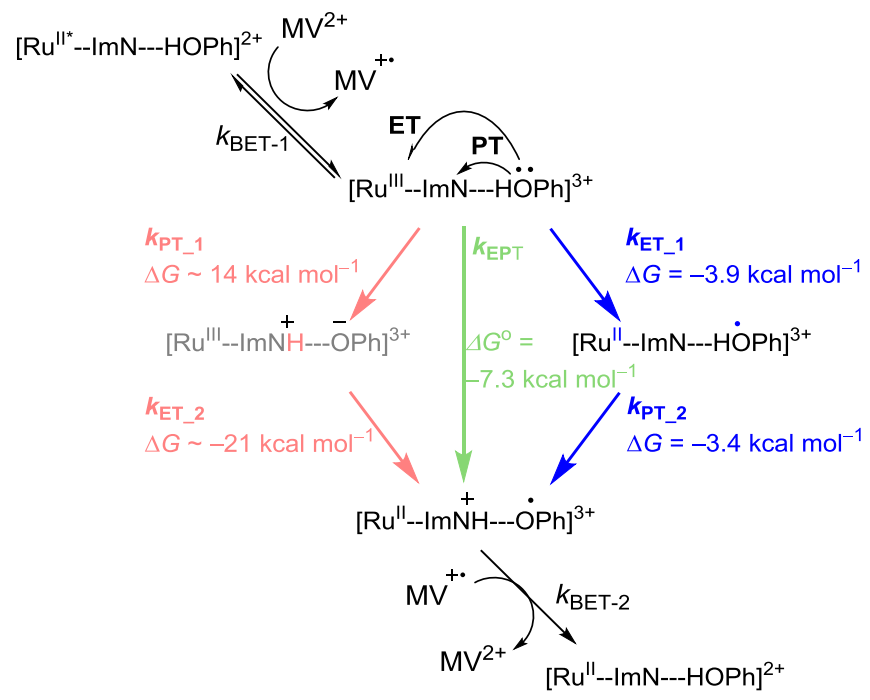

a The concerted pathway is shown in green, the ET-PT pathway in blue, and the PT-ET pathway in red. The data are best described by the ET-PT pathway (see text). The recombination reaction, with rate $k_{\mathrm{BET}-2}$ is concerted. 


\section{RESULTS}

Synthesis and characterization. The reaction of 1,10phenanthroline-5,6-dione with 3,5-di-tert-butyl-salicylaldehyde and excess $\mathrm{NH}_{4} \mathrm{OAc}$ in methanol proceeded cleanly in a microwave reactor at $150{ }^{\circ} \mathrm{C}$ (Scheme 2). While this reaction is often carried out in glacial acetic acid at reflux, the reaction time was shortened in the microwave and highly pure material crystallized upon cooling. The imidazole and phenol acidic sites were methylated with $\mathrm{MeI}$ in the presence of $\mathrm{KOH}$ to yield the PCET-free ligand, phen-Im-PhOMe. Cleavage of the methyl ether ${ }^{58}$ with $\mathrm{PhSH}$ and catalytic $\mathrm{Cs}_{2} \mathrm{CO}_{3}$ provided the desired phen-Im- $\mathrm{PhOH}$ ligand. The $\mathrm{Ru}(\mathrm{II})$ complexes were prepared in the usual way by the reaction of phen-Im-PhOH/OMe with $\mathrm{Ru}\left(\mathrm{bpy}-d_{8}\right)_{2} \mathrm{Cl}_{2}$ in ethanol/water, and the deuterated bipyridine was chosen only for the purpose of simplifying the ${ }^{1} \mathrm{H}$ NMR spectra. The $\mathrm{OH}$ proton of $\mathrm{Ru}$-phen-Im-PhOH resonates sharply at $11.24 \mathrm{ppm}$ in dry $\mathrm{CD}_{3} \mathrm{CN}$ and remains sharp with added methanol or water indicating a strong N---HOPh hydrogen bond resistant to exchange in protic solvents. Indeed, the strength of this hydrogen bond (estimated as $9 \mathrm{kcal} \mathrm{mol}^{-1}$ in the literature $)^{49}$ complicated preparation of the deuterated phenol PhOD complex by passive exchange in $\mathrm{CD}_{3} \mathrm{OD}$ at room temperature or $50{ }^{\circ} \mathrm{C}$. Attempts to prepare the PhOD complex in $\mathrm{CD}_{3} \mathrm{CN} / \mathrm{D}_{2} \mathrm{O}$ in the presence of $\mathrm{Et}_{3} \mathrm{~N}$ also failed. Complete exchange required deprotonation with excess sodium deuteroxide, acidification with $\mathrm{DCl}$, and precipitation with $\mathrm{KPF}_{6}$ in $\mathrm{D}_{2} \mathrm{O}$ (see Supporting Information for ${ }^{1} \mathrm{H}$ NMR spectra).

Electronic absorption spectra of the $\mathrm{Ru}^{\mathrm{II}}$ complexes in $\mathrm{CH}_{3} \mathrm{CN}$ exhibit ${ }^{1}$ MLCT absorptions at $\lambda_{\max }=455 \mathrm{~nm}\left(\varepsilon \sim 17,000 \mathrm{M}^{-1}\right.$ $\left.\mathrm{cm}^{-1}\right)$ and intraligand $\pi \rightarrow \pi^{*}$ bands at $280 \mathrm{~nm}\left(\varepsilon \sim 90,000 \mathrm{M}^{-1}\right.$ $\mathrm{cm}^{-1}$ ) typical for $\mathrm{Ru}^{\text {II }}$ polypyridyl complexes (Figure S17). Steady state emission spectra exhibit $\lambda_{\max }=608 \mathrm{~nm}$ and quantum yields of emission $(\Phi)$ of $0.098,0.099$, and 0.11 for the $\mathrm{PhOMe}, \mathrm{PhOH}$, and PhOD complexes, respectively (Figure S18). The lifetime of the ${ }^{3}$ MLCT excited state is $1.5 \mu$ s for each molecule. Importantly, the similar photophysical data for Ru-phen-Im-PhOMe vs Ruphen-Im-PhOH/D eliminates intramolecular electron transfer in the excited state since such a process would attenuate the emission lifetime through quenching of the ${ }^{3}$ MLCT state. Apparently, the excited state $\mathrm{Ru}^{\mathrm{II} / \mathrm{I}}$ potential is insufficiently oxidizing to trigger the electron transfer reaction.

Scheme 2. Synthesis of the ligands and ruthenium complexes
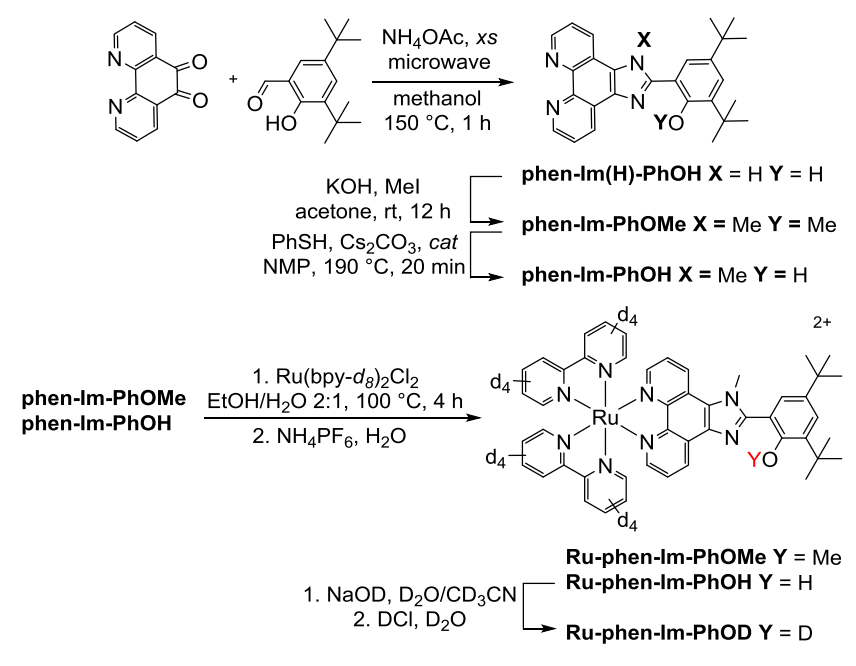

Transient absorption. Excited state transient absorption difference spectra of $\mathrm{Ru}$-phen-Im- $\mathrm{PhOH} / \mathrm{OMe}$ in $\mathrm{CH}_{3} \mathrm{CN}$ are similar and feature prominent absorptions centered at $350 \mathrm{~nm}$ and $600 \mathrm{~nm}$ and a bleach at ca. $460 \mathrm{~nm}$ (Figure S20). These features are typical of the ${ }^{3}$ MLCT excited state of $\left[\mathrm{Ru}(\mathrm{bpy})_{3}\right]^{2+}$-like complexes, ${ }^{59}$ and decay with time constants of 1.48 and $1.50 \mu \mathrm{s}$, respectively, in agreement with the emission lifetime. In the presence of methyl viologen $\left(\mathrm{MV}^{2+}\right)$, the ${ }^{3} \mathrm{MLCT}$ state is quenched oxidatively $\left(k_{\mathrm{Q}}\right.$, Scheme 1) as shown by loss of the $350 \mathrm{~nm}$ excited state absorbance and growth of $\mathrm{MV}^{+\bullet}$ absorbances at 390 and $610 \mathrm{~nm}$.

At low $\mathrm{MV}^{2+}$ concentrations (e.g. $5 \mathrm{mM}$ ), the intramolecular PCET step is not distinguishable from quenching (see Figure S21 and the detailed explanation); however, the rate of oxidative quenching of the ${ }^{3}$ MLCT state by $\mathrm{MV}^{2+}$ can exceed the rate of intramolecular PCET if a sufficient excess of $\mathrm{MV}^{2+}$ is used. SternVolmer quenching constants, $k_{\mathrm{Q}}$, on the order of $1.4 \times 10^{9} \mathrm{M}^{-1} \mathrm{~s}^{-1}$ were measured indicating that the ${ }^{3}$ MLCT lifetime could be reduced below the limit of the laser pulse with $100 \mathrm{mM} \mathrm{MV}^{2+}$. Figure 1 shows the $50 \mathrm{~ns}$ and $200 \mathrm{~ns}$ transient spectra of Ru-phen-Im$\mathrm{PhOH} / \mathrm{OMe}$ and kinetic traces at $390 \mathrm{~nm}$ and $460 \mathrm{~nm}$. After $50 \mathrm{~ns}$, the quenching reaction is complete and the spectra show $\mathrm{MV}^{+}$ absorptions and the $\mathrm{Ru}^{\mathrm{III}}$ bleach for both molecules. At $200 \mathrm{~ns}$ these features are unchanged in the PhOMe complex, while the $460 \mathrm{~nm}$ bleach of the $\mathrm{PhOH}$ complex is absent and a new weak absorption appears at $420 \mathrm{~nm}$. The kinetics at $460 \mathrm{~nm}$ are well modeled by a biexponential fit that includes a fast temperature independent component of $6 \mathrm{~ns}$, which is the instrument response, and a temperature dependent component with a time constant of $2.6 \times 10^{7} \mathrm{~s}^{-1}$ at $19^{\circ} \mathrm{C}$. Equivalent rates were also obtained from the growth of absorptions at 390 or $420 \mathrm{~nm}$ indicating the appearance of these features coincides with disappearance of the $\mathrm{Ru}^{\mathrm{III}}$. The system is completely reversible, and a single sample can be exposed to hundreds of laser pulses with no change in the ground state UV-vis absorption spectrum.
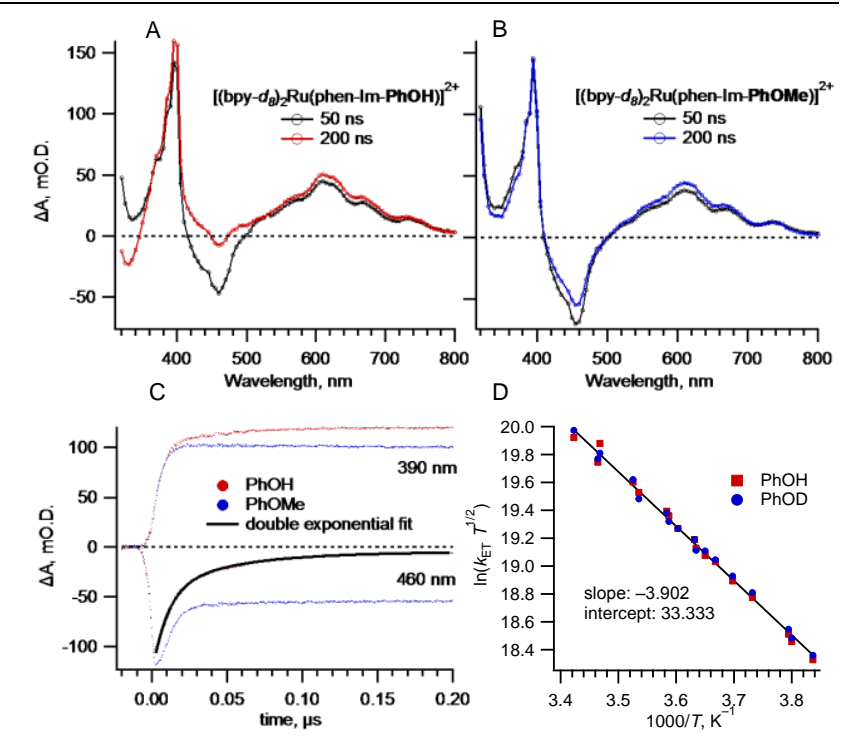

Figure 1. (A) Transient absorption spectra of Ru-phen-Im-PhOH 50 and $200 \mathrm{~ns}$ after the laser pulse. (B) Transient absorption spectra of Ru-phen-Im-PhOMe 50 and $200 \mathrm{~ns}$ after the laser pulse. (C) Kinetic traces at 390 and $460 \mathrm{~nm}$ at $13{ }^{\circ} \mathrm{C}$. The black trace is a double exponential fit of the $460 \mathrm{~nm}$ decay used to calculate the rate constant. (D) Plots of $\ln \left(\mathrm{k}_{\mathrm{et}} T^{1 / 2}\right)$ vs $T^{-1}$ used to determine the reorganization energy, $\lambda$, for electron transfer (see text). Each experiment was performed in dry $\mathrm{CH}_{3} \mathrm{CN}$ with $[\mathrm{Ru}]=30 \mu \mathrm{M}$, $\left[\mathrm{MV}^{2+}\right]=0.1 \mathrm{M}$, and $\left[\mathrm{Bu}_{4} \mathrm{NPF}_{6}\right]=0.1 \mathrm{M}$.

The disappearance of the $\mathrm{Ru}^{\mathrm{III}}$ transient bleach at $460 \mathrm{~nm}$ and the appearance of absorptions from 390-420 nm consistent with the phenoxyl radical support a net PCET oxidation of the phenol to regenerate $\mathrm{Ru}^{\mathrm{II}}$ and the $\operatorname{Im}(\mathrm{H})^{+}-\mathrm{PhO}^{\circ}$ phenoxyl radical. The 
phenoxyl radical signature is visible on the difference spectrum since the extinction coefficient of the tyrosyl radical of $\sim 3000 \mathrm{M}^{-1}$ $\mathrm{cm}^{-1}$ is approximately $7 \%$ of value for the $\mathrm{MV}^{+\bullet}\left(41800 \mathrm{M}^{-1}\right.$ $\left.\mathrm{cm}^{-1}\right){ }^{60,61}$ The kinetics of the PCET reaction were investigated as a function of temperature using the protio $\mathrm{PhOH}$ and deuterio $\mathrm{PhOD}$ isotopologues and the results are presented as a modified Arrhenius plot in Figure 1D. A kinetic isotope effect (KIE, $k_{\mathrm{H}} / k_{\mathrm{D}}$ ) of $0.99 \pm 0.03$ was obtained over the accessible temperature range of -13 to $+20^{\circ} \mathrm{C}$, and the linear fit in Figure 1D includes $\mathrm{OH}$ and OD data points. Among synthetic models of the $\mathrm{Tyr}_{\mathrm{z}} / \mathrm{His}$ pair in PSII, the absence of a KIE is rare. In $\mathrm{Tyr}_{\mathrm{z}}$ oxidation in PSII, the ns phase shows no KIE, but the $\mu$ s component does. ${ }^{17,18}$ To the best of our knowledge, the only other model with an internal base and lacking a KIE is a closely related phenol-benzimidazole-porphyrin complex. $^{38}$ However, that result is questionable because the measurement was performed by cyclic voltammetry $(\mathrm{CV})$ in $\mathrm{CH}_{3} \mathrm{CN}$ with $2 \% \mathrm{CH}_{3} \mathrm{OH}$ or $\mathrm{CD}_{3} \mathrm{OD}$. We found that the strongly $\mathrm{H}$-bonded phenol-benzimidazole proton will not exchange in $\mathrm{CH}_{3} \mathrm{CN} / \mathrm{CD}_{3} \mathrm{OD}$. In certain cases, where bulk solvent is the proton acceptor, there is no $\mathrm{KIE}$ at low $\mathrm{pH}$, rates were $\sim 10^{3} \mathrm{~s}^{-1}$, and a stepwise ET-PT mechanism was proposed. ${ }^{33}$ Analysis of Figure $1 \mathrm{D}$ is essential for elucidating the PCET mechanism (stepwise or concerted, Scheme 1) and for characterizing the thermodynamic parameters (see Discussion).

Finally, the recombination reaction between $\left[\mathrm{Ru}^{\mathrm{III}}\right.$-phen-Im$\mathrm{PhOMe}^{3+}$ or $\left.\left[\mathrm{Ru}^{\mathrm{II}} \text {-phen-Im(H) }\right)^{+}-\mathrm{PhO}^{\bullet}\right]^{3+}$ with $\mathrm{MV}^{+\bullet}$ was studied. In each case, second order equal concentration kinetics are observed (Figure 2A). The fastest reaction occurred between the $\left[\mathrm{Ru}^{\mathrm{III}} \text { phen-Im-PhOMe }\right]^{3+} / \mathrm{MV}^{+\bullet}$ pair near the diffusional limit with a rate of $1.7 \times 10^{10} \mathrm{M}^{-1} \mathrm{~s}^{-1}$ at $25^{\circ} \mathrm{C}$. The reaction of $\mathrm{MV}^{+\bullet}$ with the $\operatorname{Im}(\mathrm{H} / \mathrm{D})^{+}-\mathrm{PhO}^{\circ}$ radicals revealed an inverse $\mathrm{KIE}$ of 0.54 with $k_{\text {BET_2 }}=5.9 \times 10^{9} \mathrm{M}^{-1} \mathrm{~s}^{-1}$ and $1.1 \times 10^{10} \mathrm{M}^{-1} \mathrm{~s}^{-1}$ for the protio and deuterio complexes, respectively, at $25^{\circ} \mathrm{C}$. The inverse KIE suggests a stepwise PT-ET or concerted EPT mechanism in this case. Figure 2B shows a modified Arrhenius plot of the data which, as for the intramolecular PCET reaction, was used to analyze the mechanism and thermodynamics of the intermolecular PCET reduction of the phenoxyl radicals by the $\mathrm{MV}^{+\bullet}$ (see Discussion).

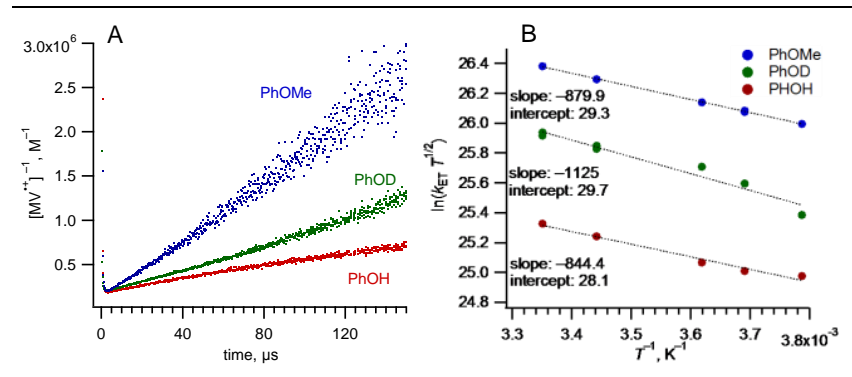

Figure 2. (A) Second-order kinetics for the recombination reaction between $\left[\mathrm{Ru}^{\mathrm{III}} \text {-phen-Im-PhOMe }\right]^{3+}$ or $\left[\mathrm{Ru}^{\mathrm{II}} \text {-phen-Im(H/D }\right)^{+}-$ $\left.\mathrm{PhO}^{\circ}\right]^{3+}$ with $\mathrm{MV}^{+\cdot}$ at $8.2{ }^{\circ} \mathrm{C}$ in $\mathrm{CH}_{3} \mathrm{CN}$ monitored by the disappearance of the $\mathrm{MV}^{+\bullet}$ absorbance at $607 \mathrm{~nm}$. (B) Temperature dependence of the recombination reaction.

Electrochemistry. The redox potentials for the $\mathrm{Ru}^{\mathrm{III} / \mathrm{II}}$, $\mathrm{PhOH} / \mathrm{PhOH}^{+\bullet}$, and $\mathrm{PhOH} / \mathrm{PhO}^{\bullet}$ couples are needed to determine the driving force for PCET oxidation and were determined by cyclic and square wave voltammetry (Figure 3 and Figures S2327). The $\mathrm{CV}$ of the phen-Im-PhOMe ligand shows sequential irreversible oxidations at $E_{\mathrm{p}}{ }^{\mathrm{a}}=1.52$ and $1.86 \mathrm{~V}$. The $\mathrm{CV}$ of the phen-Im- $\mathrm{PhOH}$ ligand shows an electrochemically irreversible, but chemically reversible, couple with $E_{\mathrm{p}}{ }^{\mathrm{a}}=1.19 \mathrm{~V}$ and $E_{\mathrm{p}}{ }^{\mathrm{c}}=0.12$ $\mathrm{V}$ and an irreversible couple at $1.58 \mathrm{~V}$ (Figure S23).
Three oxidative processes are observed for $\mathrm{Ru}$-phen-Im- $\mathrm{PhOH}$ in $\mathrm{CH}_{3} \mathrm{CN}$ : a highly distorted electrochemically irreversible, but chemically reversible wave 1 (the original species is regenerated upon reduction) with $E_{\mathrm{p}}{ }^{\mathrm{a}}=1.13 \mathrm{~V}$ and $E_{\mathrm{p}}{ }^{\mathrm{c}}=-0.07 \mathrm{~V}$, an irreversible wave 2 with $E_{\mathrm{p}}{ }^{\mathrm{a}}=1.27 \mathrm{~V}$, and a reversible $\mathrm{Ru}^{\mathrm{III} / \mathrm{II}}$ couple at $E^{\mathrm{o}}=1.35 \mathrm{~V}$ that is shifted anodically from the Ru-phen-ImPhOMe reference with $E^{0}=1.28 \mathrm{~V}$. The $0.08 \mathrm{~V}$ shift is attributed to strong coupling to the preceding oxidations. The total current for waves 1 and 2 is roughly equivalent to the current of the $\mathrm{Ru}^{\mathrm{III} / \mathrm{II}}$ couple as shown in Figure 3A.

The effect of strong acid or base on waves 1 and 2 was investigated (Figure 3B). In the presence of triflic acid, the imidazole ring is protonated, and wave 1 is absent while the current for wave 2 is larger. If $\mathrm{Bu}_{4} \mathrm{NOH}$ is added, the phenol is deprotonated, and an irreversible phenoxide oxidation is observed at $0.23 \mathrm{~V}$. These $\mathrm{acid} / \mathrm{b}$ ase reactions and their associated electrochemical responses are reversible: a $\mathrm{CV}$ recorded after acidification of the $\mathrm{Bu}_{4} \mathrm{NOH}$ solution was identical to the red trace in Figure 3B.

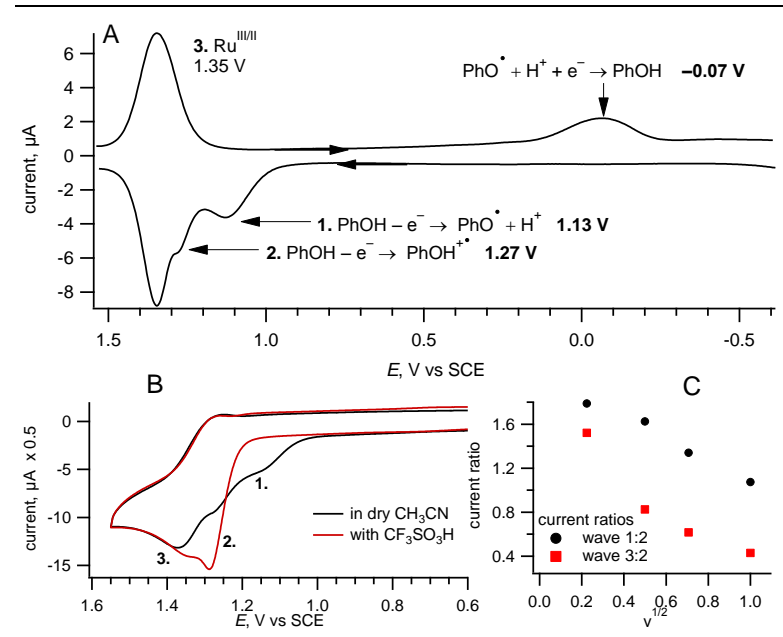

Figure 3. (A) Square wave voltammetry of Ru-phen-Im- $\mathrm{PhOH}$ (1 $\mathrm{mM}$ ) with a cathodic (top) or anodic (bottom) sweep in $\mathrm{CH}_{3} \mathrm{CN}$ at a glassy carbon electrode. (B) Oxidations $(2 \mathrm{mM})$ in $\mathrm{CH}_{3} \mathrm{CN}$ or in the presence of $\mathrm{CF}_{3} \mathrm{SO}_{3} \mathrm{H}$. (C) Scan rate-dependent plots of the ratios of current for peaks 1 and 3 vs peak 2 .

Next, the relationships among waves 1,2 , and 3 were investigated by changing the sweep rate $(v)$. The total current observed at the peak potential of peak 3 is proportional to $v^{1 / 2}$ as expected for a diffusion controlled process; however, the ratio of current for peaks $1: 2$ or 3:2 varies inversely with $v^{1 / 2}$ (Figure 3C). This observation provides evidence that waves 1 and 2 are not sequential $1 \mathrm{e}^{-}$oxidations. It also negates an associated chemical step according to an ECE mechanism since the ratio of current at waves 1:2 would be largest at fast scan rates, the opposite of what is observed here. Instead, the data suggest that the distorted response of wave 1 is due to slow oxidation kinetics, as indicated by the large separation between anodic and cathodic peaks while wave 2 is a fast oxidation step which dominates at fast sweep rates. Both oxidations 1 and 2 yield the same product, and after passage through peak 2 , the molecule is oxidized by 1 electron. Assignment of these processes will be provided in the Discussion.

\section{DISCUSSION}

Electrochemistry. An accurate assignment of the electrochemical behavior presented in Figure 3 is needed for understanding the transient absorption data in Figures 1 and 2. Comparison of $\mathrm{CV}$ data for the free $\mathrm{PhOMe}$ and $\mathrm{PhOH}$ ligands shows that the imidazole/imidazolyl oxidation occurs at 1.52 and $1.58 \mathrm{~V}$, respec- 
tively. The electrochemically irreversible couple $\left(\Delta E_{\mathrm{p}}=1.07 \mathrm{~V}\right)$ of the phen-Im- $\mathrm{PhOH}$ is assigned as concerted EPT oxidation of the phenol with the H-bonded imidazole serving as the proton acceptor. The reaction is chemically reversible as shown by the regeneration of the original species upon reduction. Waves 1 and 2 of $\mathrm{Ru}$-phen-Im-PhOH are not sequential oxidations or oxidation by an ECE mechanism as shown by scan-rate dependent current ratios. Wave 1 is highly distorted $\left(\Delta E_{\mathrm{p}}=1.2 \mathrm{~V}, E_{1 / 2}=0.53 \mathrm{~V}\right)$, is absent in the presence of a strong acid, and is absent in the Ruphen-Im-OMe control complex. These observations and comparison to the $\mathrm{CV}$ to the phen-Im- $\mathrm{PhOH}$ ligand show that waves 1 and 2 are the $\mathrm{CV}$ response to phenol oxidation. The similarity between wave 1 and the free ligand support assignment of wave 1 as the PCET oxidation of the complex.

While waves 1 and 2 are undoubtedly related to the phenol oxidation, the appearance of two waves and the large $\Delta E_{\mathrm{p}}$ of wave 1 are curious features. The PCET oxidation of a hydrogen bonded phenol typically exhibits a reversible or quasi-reversible wave. $^{50,62-64}$ For example, the series of phenol-benzimidazoles differing by protonation exhibit reversible oxidations at 0.21 , 0.94 , and $1.19 \mathrm{~V}$ for the anionic phenolate, the neutral compound, and the protonated benzimidazolium, respectively. ${ }^{64}$ The complex closely related to Ru-phen-Im-PhOH which differs by the $\mathrm{N}(\mathrm{H})$ vs $\mathrm{N}\left(\mathrm{CH}_{3}\right)$ imidazole exhibits a reversible oxidation at $1.09 \mathrm{~V}$ vs SCE. ${ }^{36}$ To the best of our knowledge, irreversible oxidation of $\mathrm{H}-$ bonded phenol was observed in only one paper for a series of four $\mathrm{Ru}(\mathrm{II})$ complexes (Chart $1, \mathrm{~B}) .^{34}$ In this particular paper, the oxidative $\mathrm{CV}$ data were collected by sweeping through the $\mathrm{Ru}$ couple and ending at $0 \mathrm{~V}$ vs $\mathrm{Fc}^{+/ 0}\left(\mathrm{Fc}^{+/ 0}=0.4 \mathrm{~V}\right.$ vs SCE$)$. Therefore, it is unclear if a peak associated with reduction of the phenoxyl radical could have been detected at a more negative potential.

In the present case, the $E_{\mathrm{p}}$ a of wave 1 is found in approximate agreement with the potentials of $E^{o}$ for reversible oxidations ${ }^{64}$ or $E_{\mathrm{p}}{ }^{\mathrm{a}}$ of irreversible oxidations ${ }^{34}$ previously assigned as PCET oxidation with proton transfer to $\mathrm{H}$-bonded bases and a similar assignment is warranted here. We postulate that the electrochemical irreversibility observed in this work is attributed in part to the N(1)-methyl benzimidazole which: (1) induces a $29^{\circ}$ torsion angle between the imidazole and phenol rings through steric repulsion with $\mathrm{H}_{6}$ of the phenol according to the optimized DFT geometry (Figure S28), and may contribute to the reorganization energy for phenoxyl radical reduction; and (2) raises the $\mathrm{p} K_{\mathrm{a}}$ of the conjugate acid of the free nitrogen. A second factor is back-bonding from the $\mathrm{Ru}(\mathrm{II})$ which will also increase the $\mathrm{p} K_{\mathrm{a}}$ in the conjugated system. The basicity of the $\mathrm{N}$ atom is reflected in the asymmetry of the H-bond according to DFT calculations of the $v\left(\mathrm{NH}^{+}---\mathrm{O}^{\circ}\right)$. The calculated value of $3454 \mathrm{~cm}^{-1}$ agrees well with the experimentally observed imidazolium stretch of PSII, suggesting that the harmonic approximation of the calculation is reasonable for a localized, $\mathrm{NH}^{+}$stretching frequency favoring the $\mathrm{N}$ atom. ${ }^{65} \mathrm{Com}-$ bined, these factors contribute to the slow kinetics for the concerted EPT redox couple.

Finally, the identity of the irreversible wave at $1.27 \mathrm{~V}$ is assigned by considering its current relative to the $\mathrm{PhOH} / \mathrm{PhO}{ }^{\circ} \mathrm{EPT}$ wave. As the scan rate is decreased, current for the EPT oxidation increases at the expense of wave 2 suggesting these two waves correspond to competing processes. Second, when the protonated imidazolium cation cannot act as the proton acceptor for phenol oxidation, the $\mathrm{PhOH} / \mathrm{PhO}^{*}$ couple is absent, and wave 2 remains with enhanced current. We then assign wave 2 as a pure electron transfer oxidation of the phenol $\left(\mathrm{PhOH}^{+/ 0}\right)$, with irreversibility due to the rapid proton loss. In the presence of acid, the bulk medium is the proton acceptor and no associated cathodic wave was observed. Wave 2 is observable in the absence of acid simply because electron transfer at wave 1 is slow in the EPT oxidation.
The calculated potential of $1.11 \mathrm{~V}$ for the $\mathrm{PhOH}^{+/ 0}$ is found in reasonable agreement to the experimental value of $1.27 \mathrm{~V}$.

The $\mathrm{Ru}^{\mathrm{III} / \mathrm{II}}$ potential is coupled to phenol oxidation and is therefore shifted relative to $E^{\mathrm{o}}$ of $\mathrm{Ru}^{\text {III/III }}$-phen-Im-PhOMe. In the quenching experiment, $\mathrm{Ru}^{\mathrm{III}}$ is obtained without prior phenol oxidation. Thus, for analysis of $\Delta G^{\mathrm{o}}$, we assume the $\mathrm{Ru}^{\mathrm{III} / \mathrm{II}}$ potential is equivalent to the control OMe complex of $E^{0}=1.28 \mathrm{~V}$, which was accurately reproduced by DFT calculations. Oxidation of the phenol by EPT or ET-PT pathways is thus favorable given assignment of waves 1 and 2 as the $\mathrm{PhOH} / \mathrm{PhO}^{\circ}$ and $\mathrm{PhOH}^{+/ 0}$ couples. Excited state intramolecular quenching is an uphill reaction (see SI) and does not compete with quenching by $\mathrm{MV}^{2+}$ as shown by the identical emission lifetimes of Ru-phen-Im-PhOH/OMe.

Phenol Oxidation. Assignment of standard potentials to the $\mathrm{Ru}^{\mathrm{III} / \mathrm{II}}$ couple and phenol oxidations by concerted or stepwise pathway allows analysis of the kinetic data obtained in the TA experiment and scrutiny of the mechanism. We propose a stepwise ET-PT mechanism with rate limiting ET according to the following arguments. Fast proton loss from a phenoxyl radical cation is expected since these species are highly acidic in $\mathrm{CH}_{3} \mathrm{CN}$ with $\mathrm{p} K_{\mathrm{a}}$ values $<0{ }^{66}$ The rapid rates measured here are supportive of a stepwise ET-PT mechanism since the concerted pathway comes at a kinetic expense due to simultaneous proton and electron movement in the transition state. For example, similar phenol-base EPT oxidations are more sluggish $\left(\sim 10^{5} \mathrm{~s}^{-1}\right)$ even though the driving forces of 0.25 to $0.44 \mathrm{eV}$ are up to five times larger than observed in the present work. ${ }^{34}$ The absence of a KIE is also a reasonable argument against the concerted EPT mechanism; however, EPT without a KIE is possible if there is no barrier to PT or if excited vibronic states with low energy vibrational modes contribute significantly to the rate. ${ }^{46}$ The absence of temperature effects on the KIE disfavors involvement of excited states in EPT oxidation, but does not rule out activationless proton transfer. Furthermore, analysis of the rate in the Marcus framework yields the most reasonable reorganizational and activation energies if the stepwise ET-first pathway is considered and DFT calculations reveal that the $\left[\mathrm{Ru}^{\mathrm{II}} \text {-phen-Im- } \mathrm{PhOH}^{+\bullet}\right]^{3+}$ species is a local minimum on the potential energy surface (Scheme 1).

The PT-ET pathway is disfavored according to the following: (1) the absence of a KIE disfavors PT in the rate limiting step; (2) the difference in phenol $\left(\mathrm{p} K_{\mathrm{a}} \sim 27\right)^{67}$ and benzimidazolium $\left(\mathrm{p} K_{\mathrm{a}} \sim\right.$ 17) ${ }^{68} \mathrm{p} K_{\mathrm{a}}$ values suggests an equilibrium constant for $\mathrm{PT}$ of $10^{-\triangle \mathrm{p} K \mathrm{a}}=10^{-10}$ and eliminates PT-ET with rate limiting ET (this approximation assumes equivalent $\mathrm{H}$-bond stabilization in the $\mathrm{N}$-$-\mathrm{HO}$ and $\mathrm{NH}^{+}--\mathrm{O}^{\bullet}$ forms); and (3) the driving force for ET in a PT-ET mechanism is approximately $1.13 \mathrm{eV}$ since $E_{(\mathrm{PhO}-/ \mathrm{PhO} \cdot)}^{\mathrm{o}}$, the potential of the phenolate couple, is now relevant. Computation of $\lambda$ (see below) with $\Delta G^{0}=-1.13 \mathrm{eV}$ gives the unreasonable value of $\lambda>3.2 \mathrm{eV}$.

As an initial approach to characterizing the ET reaction, the data were analyzed using the semiclassical Marcus equation for nonadiabatic electron transfer, equation 1 ,

$$
\begin{aligned}
& k_{N A D}=v_{e l} \exp \left(\frac{-\left(\Delta G^{0}+\lambda_{D A}\right)^{2}}{4 \lambda k_{B} T}\right) \\
& v_{e l}=\frac{4 \pi^{2}\left|H_{D A}\right|^{2}}{h \sqrt{4 \pi \lambda_{D A} k_{B} T}}
\end{aligned}
$$

where $\Delta G^{\mathrm{o}}$ is the free energy change for electron transfer, $\lambda_{\mathrm{DA}}$ is the total nuclear reorganizational energy (equal to the sum of $\lambda_{\mathrm{m}}$, the energy required for reorientation of the medium, and $\lambda_{\text {in }}$, the energy of high frequency distortions of the reactants), $H_{\mathrm{DA}}$ is the electronic coupling element between the donor $\left(\mathrm{Ru}^{\mathrm{III}}\right)$ and acceptor (the phenol), and $v_{\mathrm{el}}$ is the frequency of electron hopping in the intersection region. ${ }^{69-71}$ For completeness, the intercept of this Arrhenius plot yields an activation enthalpy, so there is an entropic factor, $\exp \left(-\Delta S^{\ddagger} / R T\right)$, missing from the prefactor. Given 
that this is essentially a unimolecular reaction in which the proton in the reactant is poised to transfer, one can argue that the (negative) entropy of activation is quite small and the entropic factor should be near unity. An Eyring analysis of the data yields $\Delta H^{*}=$ $6.9 \mathrm{kcal} \mathrm{mol}^{-1}(0.30 \mathrm{eV})$ and $\Delta S^{\ddagger}=-0.71 \mathrm{cal} \mathrm{mol}^{-1} \mathrm{~K}^{-1}\left(-\mathrm{T} \Delta S^{\ddagger}=\right.$ $0.009 \mathrm{eV})$ confirming acceptable omission of $\Delta S^{\ddagger}$ in the Marcus analysis. The Marcus activation energy of $\left(\Delta G^{0}+\lambda\right)^{2} / 4 \lambda$ is 6.8 $\mathrm{kcal} \mathrm{mol}^{-1}$ (see below for $\Delta G^{\mathrm{o}}$ and $\lambda$ ).

The free energy change was best estimated as the difference between the $\mathrm{Ru}^{\mathrm{III} / \mathrm{II}}$ and $\mathrm{PhOH}^{+/ 0}$ couples $(0.01 \mathrm{eV})$. From the slope and intercept of Figure 1D, $\lambda_{\mathrm{DA}}=1.36 \mathrm{eV}$ and $H_{\mathrm{DA}}=280 \mathrm{~cm}^{-1}$ $(0.035 \mathrm{eV})$. The $\lambda_{\mathrm{DA}}$ value is in reasonable agreement, though slightly high, with $\lambda_{\mathrm{DA}}=1 \mathrm{eV}$ estimated from the sum of half the reorganization energy for the self-exchange reaction of $\left[\mathrm{Ru}(\mathrm{bpy})_{3}\right]^{3+/ 2+}\left(0.4 \mathrm{eV}^{72}\right)$ and the reorganization energy for electrochemical oxidation of phenols hydrogen bonded to amines $(\sim 1$ eV). ${ }^{50,52}$ The uncertainty in $\lambda_{\mathrm{DA}}$ is approximately $12 \%$ from the error in fitting of Figure 1D. Calculations using a larger $\Delta G^{\mathrm{o}}$, i.e., $E^{\mathrm{o}}\left(\mathrm{Ru}^{\mathrm{III} / \mathrm{II}}\right)-E_{\mathrm{p}}{ }^{\mathrm{a}}\left(\mathrm{PhOH} / \mathrm{PhO}^{\circ}\right)=0.15 \mathrm{eV}$ yield values of $\lambda_{\mathrm{DA}}>1.63$ $\mathrm{eV}$, which appear large considering the above comparisons. One possible cause of an elevated value for $\lambda_{\mathrm{DA}}$ is the omission of temperature dependence of the reaction free energy. Additionally, $H_{\text {DA }}$ exceeds the approximate $200 \mathrm{~cm}^{-1}(0.025 \mathrm{eV})$ upper limit for non-adiabatic electron transfer ${ }^{70}$ and prompted further scrutiny of the kinetic description.

The rate constant for electron transfer in the adiabatic (slow solvent relaxation) limit is given by

$$
\begin{aligned}
& k_{A D}=\bar{v}_{\mathrm{m}} \exp \left(\frac{-\left(\Delta G^{0}+\lambda_{m}\right)^{2}}{4 \lambda_{m} k_{B} T}\right) \\
& \bar{v}_{\mathrm{m}}=\left(\frac{1}{\tau_{\mathrm{L}}}\right) \sqrt{\frac{\lambda_{\mathrm{m}}}{16 \pi k_{\mathrm{B}} T}}
\end{aligned}
$$

where $\bar{v}_{\mathrm{m}}$ and $\tau_{\mathrm{L}}$ are the effective relaxation frequency and the longitudinal relaxation time of the surrounding medium, respectively. Contributions from the high frequency inner-shell distortions to the reorganization energy are ignored and $\Delta G^{\circ} / \lambda_{\mathrm{m}}$ is less than $0.3 .^{73-75}$ The longitudinal relaxation time, $\tau_{\mathrm{L}}=\tau_{\mathrm{D}}\left(\varepsilon_{\mathrm{o}} / \varepsilon_{\mathrm{s}}\right)$ where $\tau_{\mathrm{D}}$ is the dielectric relaxation time and $\varepsilon_{\mathrm{o}}$ and $\varepsilon_{\mathrm{s}}$ are the static and optical dielectric constants of the solvent ${ }^{76}$ has a thermally activated temperature dependence given by $\tau_{\mathrm{L}}=\tau_{L}^{o} \exp \left(E_{\mathrm{L}} / k_{\mathrm{B}} T\right)$ where $E_{\mathrm{L}}$ is the activation energy. ${ }^{77}$ Estimated values of $E_{\mathrm{L}}$ and $\tau_{L}^{O}$ are $4.94 \mathrm{~kJ} \mathrm{~mol}^{-1}\left(413 \mathrm{~cm}^{-1}\right)$ and $31 \mathrm{fs}$ from the temperature dependence of $\varepsilon_{\mathrm{s}}$ and $\tau_{\mathrm{D}} \cdot{ }^{78}$ Substitution yields the expression for the temperature dependence of the solvent-controlled ET rate.

$$
k_{A D}=\left(\frac{1}{\tau_{L}^{o}}\right) \sqrt{\frac{\lambda_{\mathrm{m}}}{16 \pi k_{\mathrm{B}} T}} \exp \left(\frac{-\left(\Delta G^{0}+\lambda_{m}\right)^{2}-4 \lambda_{m} E_{L}}{4 \lambda_{m} k_{B} T}\right)
$$

From the slope of Figure 1D using $E_{\mathrm{L}}=4.94 \mathrm{~kJ} \mathrm{~mol}^{-1}, \lambda_{\mathrm{m}}=$ $1.16 \mathrm{eV}$ in better agreement with $1.2 \mathrm{eV}$ from the sum of the donor and acceptor reorganizational energies as discussed above. The prefactor of equation $2 \mathrm{c}$ was analyzed using the intercept of Figure $1 \mathrm{D}$ by calculating $\tau_{L}^{o}=54 \mathrm{fs}$ in reasonable agreement with the estimated value of $31 \mathrm{fs}$. Agreement here suggests the adiabatic treatment is an appropriate description of the ET reaction; however we sought to determine the magnitude of $H_{\mathrm{DA}}$ in the strongly coupled D-A pair.

A general expression for rate constants for ET controlled by small electronic coupling and slow solvent dynamics is readily obtained from a steady-state treatment of the electron transfer. ${ }^{73-}$ 75,79 Provided the reaction is in the "narrow reaction window" limit $\left(\Delta G^{\mathrm{o}} / \lambda_{\mathrm{m}}<<1\right),{ }^{77}$ the rate constant for ET proceeding via the competing nonadiabatic and adiabatic pathways is given by

$$
k_{E T}=\frac{k_{N A D}}{\left(1+k_{N A D} / k_{A D}\right)}=\frac{v_{\mathrm{el}}}{1+\left(\frac{v_{\mathrm{el}}}{\overline{\mathrm{v}}_{\mathrm{m}}}\right)} \exp \left[\frac{-\left(\Delta G^{0}+\lambda_{m}\right)^{2}}{4 \lambda_{m} k_{B} T}\right]
$$

It is apparent from equation 3 that $k_{\mathrm{ET}}=k_{N A D}$ when $\bar{v}_{m} \gg v_{e l}$ and conversely, $k_{\mathrm{ET}}=k_{A D}$ when $v_{e l} \gg \bar{v}_{m}$. Substitution of $v_{e l}$ and $\bar{v}_{\mathrm{m}}$ into equation $3 \mathrm{a}$ yields equation $3 \mathrm{~b}$.

$$
k_{E T}=\frac{\frac{4 \pi^{2}\left|H_{D A}\right|^{2}}{h \sqrt{4 \pi \lambda_{m} k_{B} T}}}{1+\left(\frac{8 \pi^{2}\left|H_{D A}\right|^{2} \tau_{L}^{o} \exp \left(\frac{E L}{k T}\right)}{h \lambda_{m}}\right)} \exp \left[\frac{-\left(\Delta G^{0}+\lambda_{m}\right)^{2}}{4 \lambda_{m} k_{B} T}\right]
$$

The $k_{\mathrm{ET}}$ vs $T$ data were fitted to equation 3 with adjustable $H_{\mathrm{DA}}$ and $\tau_{L}^{o}$ (Figure 4A). Using the lower limit for $H_{\mathrm{DA}}=280 \mathrm{~cm}^{-1}$ from the nonadiabatic equation requires $\tau_{L}^{O}=48 \mathrm{fs}$. Conversely, in the adiabatic limit, the rate constant is independent of $H_{D A}$ as the second term in the denominator becomes $\gg 1$. The upper limit of $\tau_{L}^{o}=54$ fs (equation $2 \mathrm{c}$ ) requires $H_{\mathrm{DA}} \geq 540 \mathrm{~cm}^{-1}$, which is also acceptable because the barrier lowering due to a large $H_{D A}$ can be ignored for $H_{\mathrm{DA}}<\lambda_{\mathrm{m}} / 2$ and $\Delta G^{o} \approx 0 .{ }^{80}$ Thus, we conclude 280 $\mathrm{cm}^{-1}<H_{A D}<540 \mathrm{~cm}^{-1}$ but cannot specify an exact value.

It is useful to visualize nonadiabatic and adiabatic contributions to the observed rate (equation 5). ${ }^{75}$ Figures $4 \mathrm{~B}$ and $4 \mathrm{C}$ illustrate that the reaction is strongly adiabatic using both sets of $\tau_{L}^{o} / H_{D A}$ from Figure 4A. In the lower limit of $H_{D A}=280 \mathrm{~cm}^{-1}$, minimal nonadiabatic contribution is possible. This comparison justifies using the solvent controlled equation $2 \mathrm{c}$ to determine $\lambda_{\mathrm{m}}$ from the slope of Figure 1D.

$$
\frac{1}{k_{E T}}=\frac{1}{k_{N A D}}+\frac{1}{k_{A D}}
$$
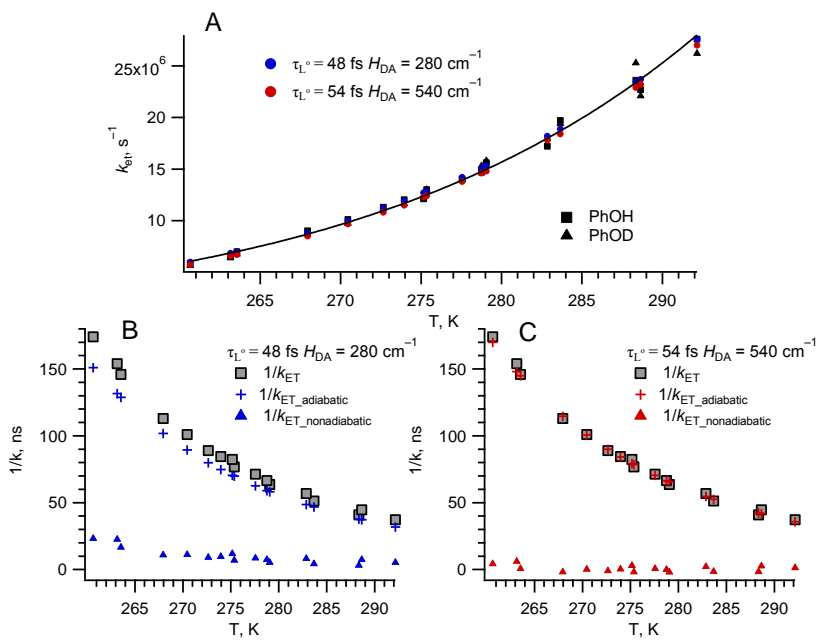

Figure 4. (A) Kinetic data for the intramolecular oxidation of the phenol by $\mathrm{Ru}^{\mathrm{III}}$ in $\mathrm{Ru}-$ phen-Im-PhOH/D fit to equation 3 using $\Delta \mathrm{G}^{\mathrm{o}}=0.01 \mathrm{eV}, \lambda_{\mathrm{m}}=1.16 \mathrm{eV}$, and $E_{\mathrm{L}}=0.051 \mathrm{eV}$. (B and C) Visualization of adiabatic and nonadiabatic contributions to the total time constant for electron transfer at the minimum $H_{D A}=280$ $\mathrm{cm}^{-1}(\mathrm{~B})$ and adiabatic limit with $\tau_{L}^{o}=54 \mathrm{fs}(\mathrm{C})$.

Table 1 Summary of Electrochemical Potentials and Kinetics of PCET Reactions.

\begin{tabular}{lllll}
\hline $\begin{array}{l}\text { Phenol } \\
\text { Oxidation }\end{array}$ & $\begin{array}{l}\mathrm{PhOH}^{0 /+} \\
(\mathrm{V})\end{array}$ & $\begin{array}{l}k_{\mathrm{ET}-\mathrm{PT}} \times \\
10^{-7}\left(\mathrm{~s}^{-1}\right)\end{array}$ & $\begin{array}{l}H_{\mathrm{DA}} \\
\left(\mathrm{cm}^{-1}\right)\end{array}$ & $\begin{array}{l}\lambda_{\mathrm{DA}} \\
(\mathrm{eV})\end{array}$ \\
$\begin{array}{l}\text { Ru-phen-Im- } \\
\text { PhOH(D) }\end{array}$ & 1.27 & 2.7 & $280-540$ & 1.16 \\
\hline $\begin{array}{l}\text { Phenoxyl } \\
\text { Radical } \\
\text { Reduction }\end{array}$ & PhOH/PhO & $k_{\mathrm{EPT}} \times$ & $V_{\mathrm{PCET}}$ & $\lambda_{\mathrm{DA}}$ \\
$\begin{array}{l}\text { Ru-phen-Im- } \\
\text { PhOH(D) }\end{array}$ & 0.53 & $10^{-9}\left(\mathrm{M}^{-1}\right.$ & $\left(\mathrm{cm}^{-1}\right)$ & $(\mathrm{eV})$ \\
& & $5.9(11)$ & $22(49)$ & 1.7 \\
\hline
\end{tabular}

${ }^{a} \mathrm{~V}$ vs $\mathrm{SCE}$ in $\mathrm{CH}_{3} \mathrm{CN} .{ }^{b} \mathrm{OD}$ values are in parenthesis. 
Phenoxyl Radical Reduction. The phenoxyl radical PCET reduction is relevant to PSII, to other biological enzymes including DNA photolyases and ribonucleotide reductases, ${ }^{81}$ and to artificial photosynthetic schemes. Both stepwise and concerted pathways have been observed in various natural or model systems. An EPT reaction facilitated by a network of strong hydrogen bonds was proposed for the reduction of $\mathrm{Tyr}_{\mathrm{z}}$ of PSII by $\mathrm{Q}_{\mathrm{A}}{ }^{-}$at $190 \mathrm{~K}^{82}$ The recombination reaction between the $\mathrm{Tyr}_{\mathrm{D}}$ (tyrosine 160) radical and $\mathrm{Q}_{\mathrm{A}}{ }^{-}$in OEC depleted PSII is a multisite concerted reaction with a normal KIE of 2-4 and rate constants $<1 \times 10^{5} \mathrm{~s}^{-1}$. $^{83}$ Proton inventory experiments revealed multiple proton donors in the radical reduction. ${ }^{84}$

Photoionization of phenol, phenolate, tyrosine, and tyrosinate yields the phenoxyl radical, a proton, and a solvated electron on the picosecond timescale. ${ }^{85-87}$ Recombination occurs with multiphasic kinetics and time constants on the order of 500 ps with the ET- first mechanism favored on entropic arguments, ${ }^{85}$ but a concerted reaction has been postulated in $\beta$-hairpin peptides where tyrosine and histidine residues interact through a cross-strand $\pi-\pi$ interaction. $^{87}$

In the absence of an exogenous reductant, the tyrosyl radical of A. nidulans DNA photolyase is reduced by $\mathrm{FADH}^{-}$(flavin adenine dinucleotide) with $t_{1 / 2}=76 \mathrm{~ms}$ in $\mathrm{H}_{2} \mathrm{O}$ or $198 \mathrm{~ms}$ in $\mathrm{D}_{2} \mathrm{O}$, suggesting a concerted mechanism, while the radical can be reduced by 2 -mercaptoethanol with a rate of $2 \times 10^{4} \mathrm{M}^{-1} \mathrm{~s}^{-1}$. 88,89 Class Ia and Ib ribonucleotide reductases facilitate radical propagation over $35 \AA$ through multiple tyrosine residues via PCET. ${ }^{90-}$

${ }^{93}$ The first observation of radical intermediates and reduction of a tyrosyl radical was achieved in a 3 -nitro tyrosine mutant. ${ }^{94}$ In this case, the radical decayed to the phenolate in an ET-first mechanism with rate constants of 283 and $67 \mathrm{~s}^{-1}$. Photoionization of tryptophan-tyrosine dipeptides at $\mathrm{pH}>12$ yields the tryptophan radical which reduced the tyrosyl radical with $k=1.2 \times 10^{5} \mathrm{~s}^{-1} .95$

The phenoxyl radical reduction in this work is a multi-site PCET with intermolecular electron transfer and intramolecular proton transfer. The free energy change for the recombination reaction between $\left[\mathrm{Ru}^{\mathrm{III}} \text {-phen-Im-PhOMe }\right]^{3+}$ and $\mathrm{MV}^{+\bullet}$ is $-1.73 \mathrm{eV}$ $\left(\mathrm{MV}^{2+/+}=-0.45 \mathrm{~V}\right)^{96}$ and the rate of $1.7 \times 10^{10} \mathrm{M}^{-1} \mathrm{~s}^{-1}$ at $25^{\circ} \mathrm{C}$ is likely diffusion controlled. For the $\left[\mathrm{Ru}^{\mathrm{II}}-\text { phen- } \mathrm{Im}(\mathrm{H})^{+}-\mathrm{PhO}^{\circ}\right]^{3+}+$ $\mathrm{MV}^{+\bullet}$ reaction, $\Delta G^{\mathrm{o}}=-0.98 \mathrm{eV}$ if the half-wave potential of the $\mathrm{PhOH} / \mathrm{PhO}^{\circ}$ couple is chosen as $E^{\circ}$. With a lower driving force the rate is significantly slower and not limited by diffusion. Assuming a diffusion-limited rate from the $\mathrm{PhOMe}+\mathrm{MV}^{+\bullet}$ data at all temperatures $\left(k_{\mathrm{BET}-1}\right)$, the activated recombination rate, $k_{\mathrm{BET}-2}$, is extracted from the measured rate, $k_{\mathrm{obs}}$ according to equation 6 .

$$
\frac{1}{k_{o b s}}=\frac{1}{k_{B E T_{-} 2}}+\frac{1}{k_{B E T_{-} 1}}
$$

For the $\mathrm{PhOH}$ and $\mathrm{PhOD}$ complexes, $k_{\mathrm{BET}-2}$ is $5.9 \times 10^{9} \mathrm{M}^{-1} \mathrm{~s}^{-1}$ and $1.1 \times 10^{10} \mathrm{M}^{-1} \mathrm{~s}^{-1}$, respectively, at $25^{\circ} \mathrm{C}$. For comparison to PSII, reduction of the tyrosyl radical by the OEC occurs with rates from 700 to $33000 \mathrm{~s}^{-1}$ and driving forces of $\sim 0.1$ to $0.2 \mathrm{eV}{ }^{6}$ The inverse $\mathrm{KIE}$ of $k_{\mathrm{H}} / k_{\mathrm{D}}=0.55$ suggests proton movement in the rate determining step. A PT-first mechanism is disfavored based on the $\mathrm{p} K_{\mathrm{a}}$ difference between the phenoxyl radical cation $(<2)$ and the imidazolium $(\sim 17)$ while an ET-first mechanism should be less sensitive to the isotope.

As a first approximation of the reorganization energy and electronic coupling element, the data were treated in the nonadiabatic electron transfer limit (equation 2), which is appropriate for EPT reactions, ${ }^{97}$ replacing $H_{\mathrm{DA}}$ with $V_{\mathrm{PCET}}$ as the product of electronic and vibronic coupling. From the slopes and intercepts of Figure 2B using $\Delta G^{\mathrm{o}}=-0.98 \mathrm{eV}, \lambda_{\mathrm{DA}}=1.7 \mathrm{eV}$ and $V_{\mathrm{PCET}}=22 \mathrm{~cm}^{-1}$ for the $\mathrm{OH}$ complex and $\lambda=1.8 \mathrm{eV}$ and $V_{\mathrm{PCET}}=49 \mathrm{~cm}^{-1}$ for the OD complex. For arguments sake, if $\Delta G^{\mathrm{o}}=-1.58 \mathrm{eV}$ (using the anodic peak potential) is considered, $\lambda_{\mathrm{DA}}$ is greater than $2.4 \mathrm{eV}$, which is larger than typical outer sphere concerted phenol oxidations. Conversely, if $\Delta G^{\mathrm{o}}=-0.38 \mathrm{eV}$ (from the cathodic peak potential) $\lambda_{\text {DA }}$ is less than $0.9 \mathrm{eV}$ and is unreasonably small since $\sim 1 \mathrm{eV}$ is expected for the phenoxyl radical reduction alone. These considerations support the choice of $E_{1 / 2}$ as $E^{o}$ for the concerted phenol oxidation potential despite its abnormally large peak-to-peak separation as discussed above.

The activation energies, as determined from the Marcus analysis, are 1.7 and $2.2 \mathrm{kcal} \mathrm{mol}^{-1}$ (590 and $790 \mathrm{~cm}^{-1}$ ), respectively for the $\mathrm{NH}^{+}$and $\mathrm{ND}^{+}$reactants in good agreement with the Arrhenius $E_{\mathrm{a}}$ values of 1.4 and $2.0 \mathrm{kcal} \mathrm{mol}^{-1}$. The $\log (\mathrm{A})$ values are $10.7\left(\mathrm{NH}^{+}\right)$and $11.5\left(\mathrm{ND}^{+}\right)$with $\log \left(\mathrm{A}^{\mathrm{H}} / \mathrm{A}^{\mathrm{D}}\right)=-0.7$.

The inverse KIE is rare in the PCET literature and deserves further discussion. An inverse solvent isotope effect of 0.5-0.7 has been observed in the concerted recombination of a photodissociated tyrosyl radical and the solvated electron, but was not observed in a PSII-inspired $\beta$-hairpin peptide. ${ }^{98}$ In this case, the solvent isotope effect was attributed to the phenolic-ammonium group interaction of tyrosine which produces a low reactant-state fractionation factor (preference for the proton) below $\mathrm{pH} 11 .^{99} \mathrm{In}$ our experiment, fractionation factors do not contribute to the observed kinetics since the $\mathrm{OH} / \mathrm{OD}$ exchange was complete prior to the experiment and there is no proton source in the acetonitrile.

To the best of our knowledge, the only other example of related behavior is a $\mathrm{Zn}$ (II) porphyrin $\mathrm{H}$-bonded to a naphthalene diimide acceptor in which normal and inverse KIEs were observed at high and low temperatures, respectively. ${ }^{100}$ While the proton promotes ET in the $\mathrm{Zn}$ (II)-naphthalene system, the proton is not formally transferred. The KIE crossover was explained considering thermal averaging of higher frequency proton vibrational states that promote the electronic coupling in the high temperature regime. At low temperature, a transition from the vibrational ground state was invoked in which the deuterium wave function better samples the fluctuations needed to promote the EPT reaction.

In the Ru-phen-Im-PhOH/D complexes the opposite behavior is observed. At low temperature a normal KIE is predicted although our experiment was limited to data far above the predicted crossover temperature of $177 \mathrm{~K}$, and the crossover temperature, while considered possible, is not overemphasized. Possible explanations for the KIE $<1$ are proposed considering the vibronic overlap between donor and acceptor, the near activationless EPT reaction, and the involvement of heavy atom low frequency vibrations as promoting modes.

The analytical rate expression for a PCET reaction is given by equation 7

$$
k_{P C E T}=
$$

$$
\sum_{\mu} P_{\mu} \sum_{\nu} \frac{\left|H_{D A} S_{\mu \nu}\right|^{2}}{\hbar} \exp \left(\frac{2 k_{B} T \alpha_{\mu \nu}^{2}}{\mathrm{M} \Omega^{2}}\right) \sqrt{\frac{\pi}{\lambda k_{B} T}} \exp \left(\frac{-\left(\Delta G_{\mu \nu}^{0}+\lambda_{D A}\right)^{2}}{4 \lambda k_{B} T}\right) \text { (7) }
$$

where $\mu$ and $v$ are reactant and product vibronic states, $P_{\mu}$ is the Boltzmann population of a reactant state, $\Delta G_{\mu v}$ is the free energy of reaction for $\mu$ and $v, S_{\mu v}$ is the overlap between wavefunctions of initial and final states, $\alpha_{\mu \nu}$ describes the exponential decay of the overlap with respect to donor-acceptor distance, $\mathrm{R}$, and $\mathrm{M}$ and $\Omega$ are the effective R-mode mass and frequency, respectively. ${ }^{43} \mathrm{~A}$ detailed calculation is beyond the scope of this manuscript; however, the calculated $\mathrm{O}-\mathrm{H}$ stretches of phenol-base compounds of $2313 \mathrm{~cm}^{-1}$ in the diabatic potential energy surface show that the H-bond of the phenol is highly symmetric and shifted to low frequency relative to phenol $\left(\mathrm{v}(\mathrm{OH}) \sim 3600 \mathrm{~cm}^{-1}\right) .{ }^{101}$ As observed here, the harmonic approximation over-estimates the stretching frequency of the phenol; however he calculated values of $v\left(\mathrm{NH}^{+}\right)$ $=3450 \mathrm{~cm}^{-1}$ and $\mathrm{v}\left(\mathrm{ND}^{+}\right)=2540 \mathrm{~cm}^{-1}$ are notably similar to the experimental values of $3250-3350 \mathrm{~cm}^{-1}$ and $2600-2400 \mathrm{~cm}^{-1}$ measured for the imidazolium NH and ND stretches of His-189 in 
PSII $^{65}$ supporting the appropriateness of the harmonic approximation for the phenoxyl radical NH/ND stretch (see SI). Since the reaction is highly exergonic, $\mathrm{PhOH} / \mathrm{D}$ vibronic excited states of the product will be involved in the reduction reaction.

The contributions of excited acceptor modes to EPT oxidation of phenols with pre-formed hydrogen bonds has been illustrated in the literature. ${ }^{101,102}$ In these examples, normal kinetic isotope effects were measured and predicted by theory; however, the greater contribution of deuterium vibrational excited modes in the product are shown in agreement with greater accessibility due to the smaller energy spacing of ND vs NH. The activation energy difference between the phenoxyl radical reduction measured here and the phenol oxidation measured is significant. For outer sphere PCET oxidation of phenol-base molecules, typical $E_{\mathrm{a}}$ values are greater than $5 \mathrm{kcal} \mathrm{mol}^{-1}$, in which case the zero point energy difference of the donor will contribute to the normal KIE. ${ }^{103}$ In our case, the PCET radical reduction reaction is nearly activationless with $E_{\mathrm{a}}=1.7$ and $2.2 \mathrm{kcal} \mathrm{mol}^{-1}\left(580\right.$ and $\left.780 \mathrm{~cm}^{-1}\right)$ for the protio and deuterio complexes which is well below the zero point energy of an $\mathrm{NH}^{+}$or $\mathrm{ND}^{+}$vibration. Further support for the stronger overlap of OD states of the acceptor with the reactant is ascertained in the difference between $V_{\text {PCET }}$ for the protio and deuterio complexes (Table 1). As the product of electronic and vibronic coupling, $V_{\text {PCET }}$ reveals stronger coupling in the deuterated complex as a contributor to the enhanced EPT rate.

Low energy vibrational modes of the heavy atoms $(\mathrm{C}, \mathrm{N}, \mathrm{O})$ can promote EPT oxidation of phenols and can reduce the KIE below that which is expected based on pure tunneling consideration in the transition state geometry. ${ }^{104}$ These particular vibrations decrease the N-O distance and have been discussed as heavy atom "gating". ${ }^{101}$ The bulk of PCET oxidation occurs for N-O distances less than the calculated transition state distance where the proton potential barrier decreases. Conversely, for large separations, pathways to excited state vibrational levels are more important.

Interestingly, DFT calculations of the $\left[\mathrm{Ru}^{\mathrm{II}}-\right.$ phen- $\operatorname{Im}(\mathrm{H} / \mathrm{D})^{+}-$ $\left.\mathrm{PhO}^{*}\right]^{3+}$ (see the SI for coordinates) reveal rocking modes at $\sim 400$ $\mathrm{cm}^{-1}$ that clearly decrease the distance between the $\mathrm{N}$-and $\mathrm{O}$ atoms suggesting these vibrations as promoting the EPT reaction. If a normal KIE occurs at low temperature, as possibly predicted from the data, it can be attributed to decreased population of excited states in the low energy heavy atom vibrations.

A KIE $<1$ is also possible if the difference in zero point energies of the transition states is smaller than in the reactants. This could occur if stronger force constants in the transition state significantly resembled the product as in the hydride transfer from a tungsten hydride to the trityl cation ${ }^{105}$ or in an equilibrium isotope effect in the rate determining step of a reaction. ${ }^{106}$ Both possibilities suggest a larger activation energy for the proton which is inconsistent with our calculated $\Delta E_{\mathrm{a}}(\mathrm{D}-\mathrm{H})$ of $0.55 \mathrm{kcal} \mathrm{mol}^{-1}$.

Finally, it is interesting to consider the implications of our results in artificial photosynthesis research. Due to the strong coupling and the adiabatic electron transfer, quenching of a photogenerated hole at a $\mathrm{Ru}^{\mathrm{III}}$ center by the appended phenol will be rapid, thus preventing charge recombination of $\mathrm{Ru}^{\text {III }}$ with a quencher or an electron injected into a semiconductor. Regeneration of the phenol through recombination is nonadiabatic in the case of the methyl viologen radical cation; however, this reaction should be adjustable based on the distance between the phenoxyl radical and its redox partner and on the driving force. The recombination of a semiconductor electron with the phenoxyl radical should be excessively slow due to the diffusion of charge in the semiconductor, while the reaction with an adjacent catalyst or charge carrier would be more rapid. Experiments to probe these hypotheses are underway.

\section{CONCLUSIONS}

The complex $\left[(\mathrm{bpy})_{2} \mathrm{Ru}-\text { phen-Im-PhOH}\right]^{2+}$ was prepared to study the intramolecular proton coupled electron transfer oxidation of the appended phenol by $\mathrm{Ru}^{\mathrm{III}}$ generated by a flash-quench experiment with methyl viologen as the oxidative quencher. The electrochemical analysis revealed interesting aspects of the phenol oxidation. Both the concerted EPT PhOH/PhO ${ }^{\circ}$ and ET-PT $\mathrm{PhOH}^{+/ 0}$ couples were observed due to the sluggishness of the concerted reaction. Importantly, the concerted oxidation was eliminated if the internal imidazole base was protonated by a strong acid. Temperature- and isotope-dependent experiments revealed the absence of a kinetic isotope effect for the rapid $\left(>10^{7} \mathrm{~s}^{-1}\right)$ PCET reaction suggesting strongly that the reaction occurs via a stepwise ET-PT mechanism despite its smaller driving force of only $c a 0.01 \mathrm{eV}$. The mechanistically simple ET-PT dominates due to the sluggishness of the multisite concerted reaction in which the electron and proton must necessarily transfer on the same potential energy minimum.

A detailed analysis of the electron transfer parameters revealed that the reaction is adiabatic due to the strong electronic coupling $\left(280<H_{\mathrm{DA}}<540 \mathrm{~cm}^{-1}\right)$ and slow solvent relaxation. The reorganization energy, $\lambda_{\mathrm{m}}$, was determined as $1.16 \mathrm{eV}$ in good agreement with the sum of $1 / 2 \lambda_{m}$ for the $\mathrm{Ru}^{\text {III/II }}$ self-exchange and $\lambda_{\mathrm{m}}$ for oxidation of model phenol compounds with hydrogen bonded proton acceptors.

As a final study, we examined the recombination reaction between the phenoxyl radical and the methyl viologen radical cation. The reaction follows equal concentration second order kinetics and occurs over several hundred milliseconds due to the low concentration of reactants formed by the laser pulse. The bimolecular rate constant is greater than $10^{9} \mathrm{M}^{-1} \mathrm{~s}^{-1}$ due to the large driving force. In this case an inverse kinetic isotope effect was observed unexpectedly and suggests an EPT mechanism. The reaction is nearly barrierless with $E_{\mathrm{a}}<2 \mathrm{kcal} \mathrm{mol}^{-1}$, and we interpret the KIE $<1$ as an indication of stronger overlap of the $v=0$ vibrational state of the donor with vibrational excited states in the product for OD. The data suggest a possible normal KIE at low temperature which is interpreted due to the depopulation of low energy heavy atom promoting vibrations. We are currently investigating the roles of solvent, imidazole $\mathrm{p} K_{\mathrm{a}}$, and phenol standard potentials on the oxidation and reduction reactions. Detailed calculations of the concerted recombination reaction will be a fruitful endeavor.

\section{EXPERIMENTAL SECTION}

General. $\left[\mathrm{Ru}\left(\mathrm{bpy}-d_{8}\right)_{2} \mathrm{Cl}_{2}\right]$ was prepared from bpy- $d_{8}$ and $\left[\mathrm{Ru}(\mathrm{COD}) \mathrm{Cl}_{2}\right]_{\mathrm{n}}$ according to the literature. ${ }^{107}$ The $\mathrm{PF}_{6}$ salt of methyl viologen $\left(\mathrm{MV}^{2+}\right)$ was prepared by anion metathesis of $\mathrm{MVCl}_{2}$ (Aldrich) with $\mathrm{NH}_{4} \mathrm{PF}_{6}$ in water, collected by filtration, and dried under vacuum. 1,10-phenanthroline-5,6-dione and 3,5-di-tertbutyl-2-hydoxybenzaldehyde were purchased from Ark Pharm Inc. Acetonitrile was Chromosolv ${ }^{\circledR}$ grade purchased from Aldrich and was dried first over an activated alumina column and then over $3 \AA$ molecular sieves activated at $350{ }^{\circ} \mathrm{C}$ under high vacuum. Prior to use, the $\mathrm{CH}_{3} \mathrm{CN}$ was vacuum transferred and stored in an $\mathrm{N}_{2}$ filled glovebox. NMR spectra were recorded on a $400 \mathrm{MHz}$ Bruker Avance spectrometer at room temperature, and chemical shifts in ppm are referenced to residual protio solvent peaks. Peak assignments are given based on analysis of ${ }^{1} \mathrm{H}$ and ${ }^{13} \mathrm{C} 1 \mathrm{D}$ spectra and COSY, HMBC, HSQC, and NOE 2D experiments. Electrospray mass spectra (ESI-MS) were measured using a Thermo Finnigan mass spectrometer. Cyclic voltammograms were recording using a three-electrode configuration with a glassy carbon or $\mathrm{Pt}$ working electrode and $\mathrm{Pt}$ counter electrode. The reference electrode was $\mathrm{Ag} / \mathrm{AgCl}(3 \mathrm{M} \mathrm{KCl})$ separated from the working solution by two Vycor frits and the supporting electrolyte was $0.1 \mathrm{M}$ 
$\mathrm{Bu}_{4} \mathrm{NPF}_{6}$. Potentials are reported versus the SCE electrode using ferrocene as an internal standard $\left(\mathrm{Fc}^{+/ 0}=0.40 \mathrm{~V}\right.$ vs SCE in $\mathrm{CH}_{3} \mathrm{CN}$ and $0.46 \mathrm{~V}$ vs SCE in $\left.\mathrm{CH}_{2} \mathrm{Cl}_{2}\right){ }^{108}$ The potential of the $\mathrm{Ag} / \mathrm{AgCl}$ electrode was $-0.017 \mathrm{~V}$ vs $\mathrm{SCE}$ in $\mathrm{CH}_{3} \mathrm{CN}$ and +0.021 $\mathrm{V}$ vs SCE in $\mathrm{CH}_{2} \mathrm{Cl}_{2}$. Analyte solutions $(1 \mathrm{mM})$ were prepared in the glovebox and transferred to the electrochemical cell under Ar. A constant flow of Ar was passed through a $\mathrm{CH}_{3} \mathrm{CN}$ bubbler and blanketed over the solution during measurements. Electronic absorption spectra were measured in a $1 \mathrm{~cm}$ quartz cell using an Agilent 8453 diode array spectrophotometer. Infrared spectra were recorded in $\mathrm{KBr}$ using a Thermo Nicolet Nexus 670 FTIR in absorption mode. Emission spectra were measured in dry, air free $\mathrm{CH}_{3} \mathrm{CN}$ using optically dilute samples in which the absorbance at the excitation wavelength $(440 \mathrm{~nm})$ was less than 0.1 . Quantum yields of emission were determined relative to $\left[\mathrm{Ru}(\mathrm{bpy})_{3}\right] \mathrm{Cl}_{2}$ in $\mathrm{CH}_{3} \mathrm{CN}\left(\Phi_{\mathrm{em}}=0.062\right)^{109}$ using the equation: $\Phi_{e m}=\Phi_{R} \frac{I_{S}}{I_{R}} \frac{A_{R}}{A_{S}}$

where the subscripts " $S$ " and "R" refer to the sample and reference respectively, $I$ is the integrated steady state emission intensity, and $\mathrm{A}$ is the absorbance at the excitation wavelength. SternVolmer quenching experiments were performed by measuring the emission lifetime of optically dilute samples in the absence $\left(I_{0}\right)$ and presence $(I)$ of varied concentrations of $\mathrm{MV}^{2+}$. Aliquots of a concentrated $\mathrm{MV}^{2+}$ solution containing the same concentration of the analyte as used for $I_{o}$ measurements were titrated into a septum-sealed quartz cuvette of analyte.

Transient Absorption. Samples for transient absorption were prepared such that the ground state absorbance at wavelengths above $350 \mathrm{~nm}$ were less than 1 and the absorbance at $440 \mathrm{~nm}$ was approximately $0.5-0.7$. All samples were prepared in dry $\mathrm{CH}_{3} \mathrm{CN}$ in air-tight Teflon sealed cuvettes and contained $0.1 \mathrm{M} \mathrm{Bu}_{4} \mathrm{NPF}_{6}$. Samples with quencher contained $0.1 \mathrm{M}$ methyl viologen. Although passive $\mathrm{OH}$ to $\mathrm{OD}$ exchange was difficult as discussed in the text, the OD to $\mathrm{OH}$ exchange appeared more facile and rigorously dried solvents were used for kinetic experiments. Samples were pumped with a continuously tunable OPO (Opotek) pumped by a Q-switched Nd:YAG at $355 \mathrm{~nm}$. The instrument was operated at $5 \mathrm{~Hz}$ with $2.5-3 \mathrm{~mJ}$ per pulse and $\sim 10 \mathrm{~ns}$ pulse width. The sample was probed at $90^{\circ}$ with a $75 \mathrm{~W}$ Xe arc lamp which was pulsed for time domains under $20 \mu$ s and not pulsed for experiments up to $2 \mathrm{~ms}$. The probe light was filtered where appropriate and focused on an ISA monochromator. The signal was detected using a Hamamatsu R955 PMT and digitized with an oscilloscope. Spectra were compiled from transients which were collected every $5 \mathrm{~nm}$ from 350 to $800 \mathrm{~nm}$ and each data point is the average of 32 kinetic traces. For temperature dependent measurements, the sample was held in a water cooled sample holder with an available temperature range of -10 to $30{ }^{\circ} \mathrm{C}$. At least 64 laser shots were averaged for the temperature-dependent kinetics. Kinetics of the recombination reaction were monitored at $607 \mathrm{~nm}$, the $\lambda_{\max }$ of the methyl viologen radical, ${ }^{61}$ and were determined by plotting $\left[\mathrm{MV}^{+\bullet}\right]^{-1}$ vs. time. Data were fit to single or double exponentials decays as appropriate with Origin ${ }^{\circledR}$ or Igor Pro ${ }^{\circledR}$ software.

DFT Calculations. Theoretical calculations were carried out using Density Functional Theory (DFT) as implemented in Gaussian09, revision D.01. ${ }^{110}$ Becke's three-parameter hybrid function$\mathrm{al}^{111-114}$ with the LYP correlation functional ${ }^{115}$ (B3LYP) was used. The LANL2 relativistic effective core potential ${ }^{116}$ and associated uncontracted basis set was used for $\mathrm{Ru}$ and the $6-311 \mathrm{G}(\mathrm{d}, \mathrm{p})$ basis set for $\mathrm{C}, \mathrm{N}, \mathrm{O}$, and $\mathrm{H}$. The solvent (acetonitrile) was modeled with the Integral Equation Formalism Polarizable Continuum Model (IEF-PCM), ${ }^{117-120}$ as implemented in Gaussian09. Universal Force Field radii (UFF) were used in all cases. The position of the unpaired electron was determined by the position of the proton in the input geometry before optimization. Frequency calculations were performed to ensure that each optimized structure is a local minimum on the potential energy surface.

2,4-di-tert-butyl-6-(1H-imidazo[4,5-f][1,10]phenanthrolin2-yl)phenol. A mixture of 1,10-phenanthroline-5,6-dione (1.00 g, $4.7 \mathrm{mmol}), 3,5$-di-tert-butyl-2-hydoxybenzaldehyde (1.11 g, 1 equiv.), and $\mathrm{NH}_{4} \mathrm{OAc}$ (3.66 g, 10 equiv.) were dissolved in $40 \mathrm{~mL}$ $\mathrm{CH}_{3} \mathrm{OH}$ and heated in a microwave reactor at $150{ }^{\circ} \mathrm{C}$ for $1 \mathrm{~h}$ with constant stirring. Upon cooling, the solution was held overnight at $5{ }^{\circ} \mathrm{C}$. A crop of yellow crystals was collected by vacuum filtration (1.16 g, 57\% yield). Additional product remained in the filtrate but was not collected. ${ }^{1} \mathrm{H}$ NMR data were identical to the literature. $^{36}$

\section{2-(3,5-di-tert-butyl-2-methoxyphenyl)-1-methyl-1H-} imidazo $[4,5-f][1,10]$ phenanthroline (phen-Im-PhOMe). A slurry of 2,4-di-tert-butyl-6-(1H-imidazo[4,5f][1,10]phenanthrolin-2-yl)phenol (1.1 g, $2.6 \mathrm{mmol})$ in acetone was treated with crushed $\mathrm{KOH}$ ( 3 equiv) and stirred under $\mathrm{Ar}$ at room temperature for $1 \mathrm{~h}$. Methyl iodide ( 3 equiv) was added by syringe and the mixture was stirred for $24 \mathrm{~h}$. The precipitate that formed was collected by vacuum filtration and dried to provide pure phen-Im-PhOMe $(0.91 \mathrm{~g}, 78 \%$ yield $) .{ }^{1} \mathrm{H} \mathrm{NMR}\left(\mathrm{CDCl}_{3}, 25\right.$ $\left.{ }^{\circ} \mathrm{C}\right): \delta 9.18-9.16(\mathrm{~m}, 2 \mathrm{H}), 9.08(\mathrm{dd}, \mathrm{J}=8.1,1.6,1 \mathrm{H}), 8.83(\mathrm{dd}, \mathrm{J}=$ 8.4, 1.3, 1H), 7.74-7.68 (m, 2H), 7.54 (2s, overlapping, $2 \mathrm{H}), 4.12$ (s, 3H, $\left.\mathrm{NCH}_{3}\right), 3.27\left(\mathrm{~s}, 3 \mathrm{H}, \mathrm{OCH}_{3}\right), 1.45(\mathrm{~s}, 9 \mathrm{H}), 1.37(\mathrm{~s}, 9 \mathrm{H}) .{ }^{13} \mathrm{C}$ $\operatorname{NMR}\left(\mathrm{CDCl}_{3}, 25{ }^{\circ} \mathrm{C}\right): \delta 156.2(\mathrm{q}), 152.9$ (q), 148.9, 147.9, 146.4 (q), 144.9 (q), 144.2 (q), 142.5 (q), 136.5 (q), 130.5, 128.2, 127.5, 126.6, 125.7 (q), 124.3 (q), 123.6, 122.7 (q), 122.6, 120.5 (q), $60.9\left(\mathrm{OCH}_{3}\right), 35.4\left(C^{\mathrm{t}} \mathrm{Bu}_{3}\right), 35.2\left(\mathrm{NCH}_{3}\right), 34.9\left(C^{t} \mathrm{Bu}_{3}\right), 31.6$ $\left({ }^{\mathrm{t}} \mathrm{Bu}_{3}\right), 30.8\left({ }^{\mathrm{t}} \mathrm{Bu}_{3}\right)$.

\section{2,4-di-tert-butyl-6-(1-methyl-1H-imidazo[4,5-} f][1,10]phenanthrolin-2-yl)phenol (phen-Im-PhOH). The phen$\mathrm{Im}-\mathrm{PhOH}$ was prepared from phen-Im-PhOMe by cleavage of the methyl ether according to a literature procedure. ${ }^{58} \mathrm{~A}$ flask was charged with phen-Im-PhOMe (0.2 g, $0.44 \mathrm{mmol})$, NMP (3 mL), benzene thiol ( $0.044 \mathrm{~mL}, 1$ equiv), $\mathrm{Cs}_{2} \mathrm{CO}_{3}(8 \mathrm{mg}, 5 \%)$, sealed with a septum and purged with argon. The mixture was then heated to $185{ }^{\circ} \mathrm{C}$ for 30 minutes. Upon cooling, $5 \mathrm{~mL}$ of water was added to induce precipitation. The solid was collected by vacuum filtration and purified by flash chromatography on basic alumina eluting with chloroform. The material collected $(0.09 \mathrm{~g}, 46 \%$ yield un-optimized) was > 95\% pure and contained a small amount of starting material. Final purification was achieved by recrystallization from hot ethanol. ${ }^{1} \mathrm{H} \mathrm{NMR}\left(\mathrm{CDCl}_{3}, 25{ }^{\circ} \mathrm{C}\right): \delta$ $11.74(\mathrm{~s}, \mathrm{OH}), 9.16(\mathrm{~m}, 2 \mathrm{H}), 8.95(\mathrm{dd}, \mathrm{J}=8.0,1.6,1 \mathrm{H}), 8.84$ (dd, J $=8.4,1.6,1 \mathrm{H}), 7.72-7.63(\mathrm{~m}, 2 \mathrm{H}), 7.49(\mathrm{~d}, \mathrm{~J}=1.4,1 \mathrm{H}), 7.45(\mathrm{~d}, \mathrm{~J}$ $=2.4,1 \mathrm{H}), 4.39\left(\mathrm{~s}, 3 \mathrm{H}, \mathrm{NCH}_{3}\right), 1.54(\mathrm{~s}, 9 \mathrm{H}), 1.40(\mathrm{~s}, 9 \mathrm{H}) .{ }^{13} \mathrm{C}$ NMR $\left(\mathrm{CDCl}_{3}, 25{ }^{\circ} \mathrm{C}\right): \delta 154.4(\mathrm{q}), 153.1(\mathrm{q}), 149.0,147.9,144.7$ (q), 144.1 (q), 140.6 (q), 137.8 (q), 134.3 (q), 130.2, 128.2, 126.3, 125.9 (q) $123.5,123.0$ (q), 122.9, 122.4, 119.7 (q), 112.2 (q), 37.4 $\left(\mathrm{NCH}_{3}\right), 35.5\left(C^{t} \mathrm{Bu}_{3}\right), 34.5\left(C^{t} \mathrm{Bu}_{3}\right), 31.7\left({ }^{t} \mathrm{Bu}_{3}\right), 29.7\left({ }^{\mathrm{t}} \mathrm{Bu}_{3}\right)$.

[(bpy-d $\left.\mathbf{d}_{\mathbf{8}}\right)_{\mathbf{2}} \mathbf{R u}($ phen-Im-PhOMe $\left.)\right]\left(\mathbf{P F}_{\mathbf{6}}\right)_{2}$. A mixture of 2:1 ethanol/water $(10 \mathrm{~mL})$ containing $\left[\mathrm{Ru}\left(\mathrm{bpy}-d_{8}\right)_{2} \mathrm{Cl}_{2}\right](55.3 \mathrm{mg}, 0.11$ $\mathrm{mmol})$ and phen-Im-PhOMe (50 mg, $0.11 \mathrm{mmol})$ was heated at reflux under air for $4 \mathrm{~h}$. Upon cooling, $5 \mathrm{~mL}$ of water containing $\sim 100 \mathrm{mg}$ sodium dithionite was added and the mixture was stirred for 30 minutes. Addition of $10 \mathrm{~mL}$ water with $\sim 0.5 \mathrm{~g} \mathrm{KPF}_{6}$ induced precipitation of a red solid which was collected by vacuum filtration and washed with water. After air drying, the solid was dissolved in $3 \mathrm{~mL} \mathrm{CH} \mathrm{Cl}_{2}$ (slurry) and $20 \mathrm{~mL}$ ether was added. The precipitate was triturated, sonicated, and filtered to provide $95 \mathrm{mg}$ of pure product in $69 \%$ yield. ${ }^{1} \mathrm{H}$ NMR $\left(\mathrm{CD}_{3} \mathrm{CN}, 25^{\circ} \mathrm{C}\right): \delta$ $9.11(\mathrm{~d}, \mathrm{~J}=8.8,1 \mathrm{H}), 9.08(\mathrm{~d}, \mathrm{~J}=8.4,1 \mathrm{H}), 8.04(\mathrm{~d}, \mathrm{~J}=5.2,2 \mathrm{H})$, 7.80-7.75 (m, 2H), $7.66(\mathrm{~d}, \mathrm{~J}=2.4,1 \mathrm{H}), 7.48(\mathrm{~d}, \mathrm{~J}=2.4,1 \mathrm{H})$, $4.15\left(\mathrm{~s}, 3 \mathrm{H}, \mathrm{NCH}_{3}\right), 3.26\left(\mathrm{~s}, 3 \mathrm{H}, \mathrm{OCH}_{3}\right), 1.48(\mathrm{~s}, 9 \mathrm{H}), 1.37(\mathrm{~s}$, 9H). ${ }^{13} \mathrm{C}$ NMR (solvent, $25^{\circ} \mathrm{C}$ ): $\delta 158.1$ (q), 158.0 (q), 157.3 (q), 155.6 (q), 151.5, 150.8, 147.1 (q), 146.8 (q), 146.6 (q), 143.6 (q), 
138.1 (q), 131.5, 131.0, 128.8, 128.0 (q), 127.8, 127.4 (q), 127.3, $126.4,123.6(\mathrm{q}), 123.3(\mathrm{q}), 61.5\left(\mathrm{OCH}_{3}\right), 36.1\left(C^{t} \mathrm{Bu}_{3}\right), 35.9$ $\left(\mathrm{NCH}_{3}\right), 35.4\left(C^{t} \mathrm{Bu}_{3}\right), 31.6\left({ }^{\mathrm{t}} \mathrm{Bu}_{3}\right), 30.9\left({ }^{\mathrm{t}} \mathrm{Bu}_{3}\right) . \operatorname{ESI}-\mathrm{MS}(+): \mathrm{m} / z$ calcd for $m / z$ calcd for $\mathrm{C}_{49} \mathrm{H}_{32} \mathrm{D}_{16} \mathrm{~F}_{6} \mathrm{~N}_{8} \mathrm{OPRu},\left(\mathrm{M}-\mathrm{PF}_{6}\right)^{+} 1027.36$, found 1027.3. Anal. Calcd for $\mathrm{C}_{49} \mathrm{H}_{32} \mathrm{D}_{16} \mathrm{~F}_{12} \mathrm{~N}_{8} \mathrm{OP}_{2} \mathrm{Ru} \cdot \mathrm{H}_{2} \mathrm{O}: \mathrm{C}$, 49.45; H, 4.24; N, 9.42. Found: C, 49.05; H, 3.73; N, 9.22. UVvis, $\mathrm{CH}_{3} \mathrm{CN}, \lambda_{\max } 455 \mathrm{~nm}\left(\varepsilon 18500 \mathrm{M}^{-1} \mathrm{~cm}^{-1}\right)$.

$\left[\left(\mathbf{b p y}-\mathbf{d}_{\mathbf{8}}\right)_{2} \mathbf{R u}(\mathbf{p h e n}-\mathbf{I m}-\mathbf{P h O H})\right]\left(\mathbf{P F}_{\mathbf{6}}\right)_{2}$. A mixture of 2:1 ethanol/water $(10 \mathrm{~mL})$ containing $\left[\mathrm{Ru}\left(\mathrm{bpy}-d_{8}\right)_{2} \mathrm{Cl}_{2}\right](42.9 \mathrm{mg}, 0.086$ $\mathrm{mmol})$ and phen-Im-PhOMe (37.3 $\mathrm{mg}, 0.09 \mathrm{mmol})$ was heated at reflux under argon for $4 \mathrm{~h}$. Upon cooling, $5 \mathrm{~mL}$ of water containing $\sim 100 \mathrm{mg}$ sodium dithionite was added and the mixture was stirred for 30 minutes. Addition of $10 \mathrm{~mL}$ water with $\sim 0.3 \mathrm{~g}$ $\mathrm{NH}_{4} \mathrm{PF}_{6}$ induced precipitation of a red solid which was collected by vacuum filtration and washed with water. After air drying, the solid was dissolved in $3 \mathrm{~mL} \mathrm{CH} \mathrm{Cl}_{2}$ (slurry) and $20 \mathrm{~mL}$ ether was added. The precipitate was triturated, sonicated, and filtered to provide $65 \mathrm{mg}$ of pure product in $65 \%$ yield. ${ }^{1} \mathrm{H}$ NMR $\left(\mathrm{CD}_{3} \mathrm{CN}\right.$, $\left.25{ }^{\circ} \mathrm{C}\right): \delta 11.24(\mathrm{~s}, 1 \mathrm{H}, \mathrm{OH}), 9.13(\mathrm{~m}, 2 \mathrm{H}), 8.07(\mathrm{~d}, \mathrm{~J}=5.2,2 \mathrm{H})$, $7.82-7.77(\mathrm{~m}, 2 \mathrm{H}), 7.63(\mathrm{~d}, \mathrm{~J}=2.4,1 \mathrm{H}), 7.59(\mathrm{~d}, \mathrm{~J}=2.4,1 \mathrm{H})$, $4.45\left(\mathrm{~s}, 3 \mathrm{H}, \mathrm{NCH}_{3}\right), 1.51(\mathrm{~s}, 9 \mathrm{H}), 1.41(\mathrm{~s}, 9 \mathrm{H}) .{ }^{13} \mathrm{C}$ NMR (solvent, $\left.25{ }^{\circ} \mathrm{C}\right): \delta 158.1(\mathrm{q}), 158.0(\mathrm{q}), 155.8(\mathrm{q}), 155.0(\mathrm{q}), 151.9,151.2$, $147.0(\mathrm{q}), 146.8(\mathrm{q}), 142.2(\mathrm{q}), 138.4$ (q), $136.2(\mathrm{q}), 131.9,131.1$, 128.7 (q), 128.0, 127.3, 126.6, 126.3 (q), 124.9, 123.3 (q), 113.2 (q), $38.4\left(\mathrm{NCH}_{3}\right), 36.1\left(C^{\mathrm{t}} \mathrm{Bu}_{3}\right), 35.2\left(C^{\mathrm{t}} \mathrm{Bu}_{3}\right), 31.7\left({ }^{\mathrm{t}} \mathrm{Bu}_{3}\right), 29.8$ $\left({ }^{\mathrm{t}} \mathrm{Bu}_{3}\right)$. ESI-MS(+): $m / z$ calcd for $\mathrm{C}_{48} \mathrm{H}_{30} \mathrm{D}_{16} \mathrm{~F}_{6} \mathrm{~N}_{8} \mathrm{OPRu},\left(\mathrm{M}-\mathrm{PF}_{6}\right)^{+}$ 1013.35, found 1013.3. Anal. Calcd for $\mathrm{C}_{48} \mathrm{H}_{30} \mathrm{D}_{16} \mathrm{~F}_{12} \mathrm{~N}_{8} \mathrm{OP}_{2} \mathrm{Ru} \cdot 2 \mathrm{H}_{2} \mathrm{O}: \mathrm{C}, 48.28 ; \mathrm{H}, 4.16 ; \mathrm{N}, 9.38$. Found: C, 48.35; H, 3.93; N, 9.77. UV-vis, $\mathrm{CH}_{3} \mathrm{CN}, \lambda_{\max } 455 \mathrm{~nm}(\varepsilon 16700$ $\left.\mathrm{M}^{-1} \mathrm{~cm}^{-1}\right)$.

[(bpy-d $\left.\left.)_{\mathbf{8}}\right)_{\mathbf{2}} \mathbf{R u}(\mathbf{p h e n}-\mathbf{I m}-\mathbf{P h O D})\right]\left(\mathbf{P F}_{\mathbf{6}}\right)_{2}$. A $40 \mathrm{mg}$ portion of $\left[\left(\mathrm{bpy}-d_{8}\right)_{2} \mathrm{Ru}(\right.$ phen-Im-PhOH$\left.)\right]\left(\mathrm{PF}_{6}\right)_{2}$ was dissolved in $1 \mathrm{~mL}$ $\mathrm{CD}_{3} \mathrm{CN}$. $\mathrm{D}_{2} \mathrm{O}(\sim 3 \mathrm{~mL})$ was added and the mixture was purged with Ar. Three drops of $40 \% \mathrm{NaOD}$ in $\mathrm{D}_{2} \mathrm{O}$ were then added. The red solution darkened slightly and a hand-held UV lamp showed no orange phosphorescence. The solution was stirred for $30 \mathrm{~min}$ then quenched with 5 drops of conc. $\mathrm{DCl}$ whereupon the color lightened and phosphorescence was evident. A saturated solution of $\mathrm{KPF}_{6}$ in $\mathrm{D}_{2} \mathrm{O}(\sim 4 \mathrm{~mL})$ was added to induce precipitation. The filtrate was collected on a glass frit by vacuum filtration, wash quickly with $4: 1 \mathrm{D}_{2} \mathrm{O} / \mathrm{CH}_{3} \mathrm{OD}(5 \mathrm{~mL})$ then diethyl ether. The solid was dried in a vacuum desiccator on the glass frit and transferred directly to a glovebox for storage without weighing. ${ }^{1} \mathrm{H}$ NMR $\left(\mathrm{CD}_{3} \mathrm{CN}, 25^{\circ} \mathrm{C}\right): \delta 9.19(\mathrm{~d}, \mathrm{~J}=8.4,1 \mathrm{H}), 9.07(\mathrm{~d}, \mathrm{~J}=8.0,1 \mathrm{H})$, $8.21(\mathrm{~d}, \mathrm{~J}=5.2,2 \mathrm{H}), 7.94-7.88(\mathrm{~m}, 1 \mathrm{H}), 7.76(\mathrm{~s}, 1 \mathrm{H}), 7.56(\mathrm{~s}$, $1 \mathrm{H}), 4.37(\mathrm{~s}, 3 \mathrm{H}), 1.51(\mathrm{~s}, 9 \mathrm{H}), 1.40(\mathrm{~s}, 9 \mathrm{H})$.

\section{ASSOCIATED CONTENT}

\section{Supporting Information}

NMR spectra, additional transient absorption data and tables of raw data, cyclic voltammograms, and coordinates of DFT structures. This material is available free of charge via the Internet at http://pubs.acs.org.

\section{AUTHOR INFORMATION}

\section{Corresponding Author}

*Email: gmanbeck@bnl.gov, jconcepc@bnl.gov

\section{Notes}

The authors declare no competing financial interests.

\section{ACKNOWLEDGMENT}

We are grateful to Drs. Norman Sutin, James T. Muckerman, and Marshall Newton for their assistance in data interpretation and for critical reading of the manuscript. The work carried out at Brookhaven National Laboratory was supported by the U.S. Department of Energy, Office of Science, Division of Chemical Sciences, Geosciences, \& Biosciences, Office of Basic Energy Sciences under contract DE-SC00112704.

\section{REFERENCES}

(1) Gust, D.; Moore, T. A.; Moore, A. L. Acc. Chem. Res. 2001, 34, 40-48.

(2) Barbara, P. F.; Meyer, T. J.; Ratner, M. A. J. Phys. Chem. 1996, 100, 13148-13168.

(3) Yonemoto, E. H.; Saupe, G. B.; Schmehl, R. H.; Hubig, S. M.; Riley, R. L.; Iverson, B. L.; Mallouk, T. E. J. Am. Chem. Soc. 1994, 116, 4786-4795.

(4) Alstrum-Acevedo, J. H.; Brennaman, M. K.; Meyer, T. J. Inorg. Chem. 2005, 44, 6802-6827.

(5) Kok, B.; Forbush, B.; McGloin, M. Photochem. Photobiol. 1970, 11, 457-475.

(6) Vinyard, D. J.; Ananyev, G. M.; Dismukes, G. C. Annu. Rev. Biochem. 2013, 82, 577-606.

(7) Renger, G.; Renger, T. Photosynth. Res. 2008, 98, 53-80.

(8) Schatz, G. H.; Brock, H.; Holzwarth, A. R. Proc. Natl. Acad. Sci. U. S. A. 1987, 84, 8414-8418.

(9) Holzwarth, A. R.; Muller, M. G.; Reus, M.; Nowaczyk, M.; Sander, J.; Rogner, M. Proc. Natl. Acad. Sci. U. S. A. 2006, 103, 6895-6900.

(10) Vrettos, J. S.; Limburg, J.; Brudvig, G. W. Biochim. Biophys. Acta. Energetics 2001, 1503, 229-245.

(11) Yachandra, V. K.; Sauer, K.; Klein, M. P. Chem. Rev. 1996, 96, 2927-2950.

(12) Vass, I.; Cser, K. Trends Plant Sci. 2009, 14, 200-205.

(13) Rutherford, A. W.; Osyczka, A.; Rappaport, F. FEBS Lett. 2012, 586, 603-616.

(14) Rappaport, F.; Guergova-Kuras, M.; Nixon, P. J.; Diner, B. A.; Lavergne, J. Biochemistry 2002, 41, 8518-8527.

(15) Tommos, C.; Babcock, G. T. Biochim. Biophys. Acta. Energetics 2000, 1458, 199-219.

(16) Ahlbrink, R.; Haumann, M.; Cherepanov, D.; Bogershausen, O.; Mulkidjanian, A.; Junge, W. Biochemistry 1998, 37, 11311142 .

(17) Schilstra, M. J.; Rappaport, F.; Nugent, J. H. A.; Barnett, C. J.; Klug, D. R. Biochemistry 1998, 37, 3974-3981.

(18) Christen, G.; Renger, G. Biochemistry 1999, 38, 2068-2077.

(19) Kuhne, H.; Brudvig, G. W. J. Phys. Chem. B 2002, 106, 8189-8196.

(20) Hays, A. M. A.; Vassiliev, I. R.; Golbeck, J. H.; Debus, R. J. Biochemistry 1999, 38, 11851-11865.

(21) Umena, Y.; Kawakami, K.; Shen, J.-R.; Kamiya, N. Nature 2011, 473, 55-U65.

(22) In this context, "PCET" is the net transfer of a proton and electron. Stepwise mechanisms are denoted "PT-ET or ET-PT", and a concerted reaction is designated as "EPT".

(23) Weinberg, D. R.; Gagliardi, C. J.; Hull, J. F.; Murphy, C. F.; Kent, C. A.; Westlake, B. C.; Paul, A.; Ess, D. H.; McCafferty, D. G.; Meyer, T. J. Chem. Rev. 2012, 112, 4016-4093.

(24) Migliore, A.; Polizzi, N. F.; Therien, M. J.; Beratan, D. N. Chem. Rev. 2014, 114, 3381-3465.

(25) Costentin, C.; Robert, M.; Saveant, J. M. Chem. Rev. 2010, 110, PR1-PR40.

(26) Concepcion, J. J.; Brennaman, M. K.; Deyton, J. R.; Lebedeva, N. V.; Forbes, M. D. E.; Papanikolas, J. M.; Meyer, T. J. J. Am. Chem. Soc. 2007, 129, 6968-6969.

(27) Wenger, O. S. Acc. Chem. Res. 2013, 46, 1517-1526. 
(28) Irebo, T.; Reece, S. Y.; Sjodin, M.; Nocera, D. G.; Hammarstrom, L. J. Am. Chem. Soc. 2007, 129, 15462-15464.

(29) Reece, S. Y.; Seyedsayamdost, M. R.; Stubbe, J.; Nocera, D. G. J. Am. Chem. Soc. 2006, 128, 13654-13655.

(30) Cohen, B. W.; Polyansky, D. E.; Achord, P.; Cabelli, D.; Muckerman, J. T.; Tanaka, K.; Thummel, R. P.; Zong, R. F.; Fujita, E. Faraday Discuss. 2012, 155, 129-144.

(31) Kuss-Petermann, M.; Wolf, H.; Stalke, D.; Wenger, O. S. J. Am. Chem. Soc. 2012, 134, 12844-12854.

(32) Pizano, A. A.; Yang, J. L.; Nocera, D. G. Chem. Sci. 2012, $3,2457-2461$.

(33) Irebo, T.; Zhang, M.-T.; Markle, T. F.; Scott, A. M.; Hammarstrom, L. J. Am. Chem. Soc. 2012, 134, 16247-16254.

(34) Zhang, M.-T.; Irebo, T.; Johansson, O.; Hammarstrom, L. J. Am. Chem. Soc. 2011, 133, 13224-13227.

(35) Irebo, T.; Johansson, O.; Hammarstrom, L. J. Am. Chem. Soc. 2008, 130, 9194-9195.

(36) Lachaud, F.; Quaranta, A.; Pellegrin, Y.; Dorlet, P.; Charlot, M.-F.; Un, S.; Leibl, W.; Aukauloo, A. Angew. Chem., Int. Ed. 2005, 44, 1536-1540.

(37) Moore, G. F.; Hambourger, M.; Gervaldo, M.; Poluektov, O. G.; Rajh, T.; Gust, D.; Moore, T. A.; Moore, A. L. J. Am. Chem. Soc. 2008, 130, 10466-10467.

(38) Megiatto, J. D.; Mendez-Hernandez, D. D.; Tejeda-Ferrari, M. E.; Teillout, A. L.; Llansola-Portoles, M. J.; Kodis, G.; Poluektov, O. G.; Rajh, T.; Mujica, V.; Groy, T. L.; Gust, D.; Moore, T. A.; Moore, A. L. Nature Chem. 2014, 6, 423-428.

(39) Megiatto, J. D.; Antoniuk-Pablant, A.; Sherman, B. D.; Kodis, G.; Gervaldo, M.; Moore, T. A.; Moore, A. L.; Gust, D. Proc. Natl. Acad. Sci. U. S. A. 2012, 109, 15578-15583.

(40) Markle, T. F.; Rhile, I. J.; Mayer, J. M. J. Am. Chem. Soc. 2011, 133, 17341-17352.

(41) Soudackov, A. V.; Hazra, A.; Hammes-Schiffer, S. J. Chem. Phys. 2011, 135, 144115.

(42) Hammes-Schiffer, S.; Stuchebrukhov, A. A. Chem. Rev. 2010, 110, 6939-6960.

(43) Hammes-Schiffer, S. Energy Environ. Sci. 2012, 5, 76967703.

(44) Hammes-Schiffer, S. Acc. Chem. Res. 2009, 42, 1881-1889.

(45) Cukier, R. I. J. Phys. Chem. 1996, 100, 15428-15443.

(46) Edwards, S. J.; Soudackov, A. V.; Hammes-Schiffer, S. J. Phys. Chem. A. 2009, 113, 2117-2126.

(47) Costentin, C.; Robert, M.; Saveant, J. M. J. Am. Chem. Soc. 2007, 129, 5870-5879.

(48) Bonin, J.; Costentin, C.; Robert, M.; Routier, M.; Saveant, J.-M. J. Am. Chem. Soc. 2013, 135, 14359-14366.

(49) Markle, T. F.; Rhile, I. J.; DiPasquale, A. G.; Mayer, J. M. Proc. Natl. Acad. Sci. U. S. A. 2008, 105, 8185-8190.

(50) Rhile, I. J.; Markle, T. F.; Nagao, H.; DiPasquale, A. G.; Lam, O. P.; Lockwood, M. A.; Rotter, K.; Mayer, J. M. J. Am. Chem. Soc. 2006, 128, 6075-6088.

(51) Bonin, J.; Costentin, C.; Robert, M.; Saveant, J.-M.; Tard, C. Acc. Chem. Res. 2012, 45, 372-381.

(52) Costentin, C.; Robert, M.; Saveant, J.-M. J. Am. Chem. Soc. 2007, 129, 9953-9963.

(53) Costentin, C.; Louault, C.; Robert, M.; Saveant, J. M. Proc. Natl. Acad. Sci. U. S. A. 2009, 106, 18143-18148.

(54) Zhao, Y.; Swierk, J. R.; Megiatto, J. D., Jr.; Sherman, B.; Youngblood, W. J.; Qin, D.; Lentz, D. M.; Moore, A. L.; Moore, T. A.; Gust, D.; Mallouk, T. E. Proc. Natl. Acad. Sci. U. S. A. 2012, 109, 15612-15616.

(55) Quaranta, A.; Lachaud, F.; Herrero, C.; Guillot, R.; Charlot, M. F.; Leibl, W.; Aukauloo, A. Chem. Eur. J. 2007, 13, 82018211.

(56) Haumann, M.; Liebisch, P.; Muller, C.; Barra, M.; Grabolle, M.; Dau, H. Science 2005, 310, 1019-1021.
(57) Razeghifard, M. R.; Pace, R. J. Biochim. Biophys. Acta. Energetics 1997, 1322, 141-150.

(58) Chakraborti, A. K.; Sharma, L.; Nayak, M. K. J. Org. Chem. 2002, 67, 6406-6414.

(59) Bensasson, R.; Salet, C.; Balzani, V. J. Am. Chem. Soc. 1976, 98, 3722-3724.

(60) Feitelson, J.; Hayon, E. J. Phys. Chem. 1973, 77, 10-15.

(61) Watanabe, T.; Honda, K. J. Phys. Chem. 1982, 86, $2617-$ 2619.

(62) Maki, T.; Araki, Y.; Ishida, Y.; Onomura, O.; Matsumura, Y. J. Am. Chem. Soc. 2001, 123, 3371-3372.

(63) Benisvy, L.; Blake, A. J.; Collison, D.; Davies, E. S.; Garner, C. D.; McInnes, E. J. L.; McMaster, J.; Whittaker, G.; Wilson, C. Dalton Trans. 2003, 1975-1985.

(64) Moore, G. F.; Hambourger, M.; Kodis, G.; Michl, W.; Gust, D.; Moore, T. A.; Moore, A. L. J. Phys. Chem. B 2010, 114, 14450-14457.

(65) Kim, S.; Liang, J.; Barry, B. A. Proc. Natl. Acad. Sci. U. S. A. 1997, 94, 14406-14411.

(66) Bordwell, F. G.; Cheng, J. P. J. Am. Chem. Soc. 1991, 113, 1736-1743.

(67) Chantooni, M. K.; Kolthoff, I. M. J. Phys. Chem. 1976, 80, 1306-1310.

(68) Izutso, K. Acid-Base Dissociation Constants in Dipolar Aprotic Solvents Blackwell: London, 1990.

(69) Marcus, R. A.; Sutin, N. Biochim. Biophys. Acta. 1985, 811, 265-322.

(70) Newton, M. D.; Sutin, N. Annu Rev. Phys. Chem. 1984, 35, 437-480.

(71) Sutin, N. Prog. Inorg. Chem. 1983, 30, 441-498.

(72) Young, R. C.; Keene, F. R.; Meyer, T. J. J. Am. Chem. Soc. 1977, 99, 2468-2473.

(73) Rips, I.; Jortner, J. J. Chem. Phys. 1987, 87, 6513-6519.

(74) Bixon, M.; Jortner, J. Chem. Phys. 1993, 176, 467-481.

(75) Rips, I.; Jortner, J. J. Chem. Phys. 1987, 87, 2090-2104.

(76) Maroncelli, M.; Macinnis, J.; Fleming, G. R. Science 1989, $243,1674-1681$

(77) Sumi, H.; Marcus, R. A. J. Chem. Phys. 1986, 84, 48944914.

(78) Mansingh, K.; Mansingh, A. J. Chem. Phys. 1964, 41, 827\&

(79) Hartmann, L.; Goychuk, I.; Hanggi, P. J. Chem. Phys. 2000, 113, 11159-11175.

(80) Brunschwig, B. S.; Sutin, N. Coord. Chem. Rev. 1999, 187, 233-254.

(81) Warren, J. J.; Mayer, J. M. Biochemistry 2015, 54, 18631878 .

(82) Keough, J. M.; Jenson, D. L.; Zuniga, A. N.; Barry, B. A. J. Am. Chem. Soc. 2011, 133, 11084-11087.

(83) Jenson, D. L.; Evans, A.; Barry, B. A. J. Phys. Chem. B 2007, 111, 12599-12604.

(84) Jenson, D. L.; Barry, B. A. J. Am. Chem. Soc. 2009, 131, 10567-10573.

(85) Oliver, T. A. A.; Zhang, Y. Y.; Roy, A.; Ashfold, M. N. R.; Bradforth, S. E. J. Phys. Chem. Lett. 2015, 6, 4159-4164.

(86) Chen, X. Y.; Larsen, D. S.; Bradforth, S. E.; van Stokkum, I. H. M. J. Phys. Chem. A. 2011, 115, 3807-3819.

(87) Pagba, C. V.; Chi, S. H.; Perry, J.; Barry, B. A. J. Phys. Chem. B 2015, 119, 2726-2736.

(88) Aubert, C.; Brettel, K.; Mathis, P.; Eker, A. P. M.; Boussac, A. J. Am. Chem. Soc. 1999, 121, 8659-8660.

(89) Aubert, C.; Mathis, P.; Eker, A. P. M.; Brettel, K. Proc. Natl. Acad. Sci. U. S. A. 1999, 96, 5423-5427.

(90) Cotruvo, J. A.; Stubbe, J. In Annual Review of Biochemistry, Vol 80; Kornberg, R. D., Raetz, C. R. H., Rothman, J. E., Thorner, J. W., Eds.; Annual Reviews: Palo Alto, 2011; Vol. 80, p 733767. 
(91) Minnihan, E. C.; Seyedsayamdost, M. R.; Stubbe, J. Biochemistry 2009, 48, 12125-12132.

(92) Seyedsayamdost, M. R.; Chan, C. T. Y.; Mugnaini, V.; Stubbe, J.; Bennati, M. J. Am. Chem. Soc. 2007, 129, 1574815749.

(93) Stubbe, J.; Nocera, D. G.; Yee, C. S.; Chang, M. C. Y. Chem. Rev. 2003, 103, 2167-2201.

(94) Yokoyama, K.; Uhlin, U.; Stubbe, J. J. Am. Chem. Soc. 2010, 132, 15368-15379.

(95) Reece, S. Y.; Stubbe, J.; Nocera, D. G. Biochim. Biophys. Acta. Energetics 2005, 1706, 232-238.

(96) Tsukahara, K.; Wilkins, R. G. J. Am. Chem. Soc. 1985, 107, 2632-2635.

(97) Schrauben, J. N.; Cattaneo, M.; Day, T. C.; Tenderholt, A. L.; Mayer, J. M. J. Am. Chem. Soc. 2012, 134, 16635-16645.

(98) Pagba, C. V.; McCaslin, T. G.; Chi, S. H.; Perry, J. W.; Barry, B. A. J. Phys. Chem. B 2016, 120, 1259-1272.

(99) Schowen, K. B.; Schowen, R. L. Methods Enzymol. 1982, 87, 551-606.

(100) Hodgkiss, J. M.; Damrauer, N. H.; Presse, S.; Rosenthal, J.; Nocera, D. G. J. Phys. Chem. B 2006, 110, 18853-18858.

(101) Markle, T. F.; Tenderholt, A. L.; Mayer, J. M. J. Phys. Chem. B 2012, 116, 571-584.

(102) Ishikita, H.; Soudackov, A. V.; Hammes-Schiffer, S. J. Am. Chem. Soc. 2007, 129, 11146-11152.

(103) Markle, T. F.; Mayer, J. M. Angew. Chem., Int. Ed. 2008, 47, 738-740.

(104) Johannissen, L. O.; Irebo, T.; Sjodin, M.; Johansson, O.; Hammarstrom, L. J. Phys. Chem. B 2009, 113, 16214-16225.

(105) Cheng, T. Y.; Bullock, R. M. J. Am. Chem. Soc. 1999, 121, 3150-3155.

(106) Churchill, D. G.; Janak, K. E.; Wittenberg, J. S.; Parkin, G. J. Am. Chem. Soc. 2003, 125, 1403-1420.

(107) Norris, M. R.; Concepcion, J. J.; Glasson, C. R. K.; Fang, Z.; Lapides, A. M.; Ashford, D. L.; Templeton, J. L.; Meyer, T. J. Inorg. Chem. 2013, 52, 12492-12501.

(108) Connelly, N. G.; Geiger, W. E. Chem. Rev. 1996, 96, 877910.

(109) Caspar, J. V.; Meyer, T. J. Inorg. Chem. 1983, 22, 24442453.

(110) Frisch, M. J.; Trucks, G. W.; Schlegel, H. B.; Scuseria, G. E.; Robb, M. A.; Cheeseman, J. R.; Scalmani, G.; Barone, V.; Mennucci, B.; Petersson, G. A.; Nakatsuji, H.; Caricato, M.; Li, X.; Hratchian, H. P.; Izmaylov, A. F.; Bloino, J.; Zheng, G.; Sonnenberg, J. L.; Hada, M.; Ehara, M.; Toyota, K.; Fukuda, R.; Hasegawa, J.; Ishida, M.; Nakajima, T.; Honda, Y.; Kitao, O.; Nakai, H.; Vreven, T.; Montgomery Jr., J. A.; Peralta, J. E.; Ogliaro, F.; Bearpark, M. J.; Heyd, J.; Brothers, E. N.; Kudin, K. N.; Staroverov, V. N.; Kobayashi, R.; Normand, J.; Raghavachari, K.; Rendell, A. P.; Burant, J. C.; Iyengar, S. S.; Tomasi, J.; Cossi, M.; Rega, N.; Millam, N. J.; Klene, M.; Knox, J. E.; Cross, J. B.; Bakken, V.; Adamo, C.; Jaramillo, J.; Gomperts, R.; Stratmann, R. E.; Yazyev, O.; Austin, A. J.; Cammi, R.; Pomelli, C.; Ochterski, J. W.; Martin, R. L.; Morokuma, K.; Zakrzewski, V. G.; Voth, G. A.; Salvador, P.; Dannenberg, J. J.; Dapprich, S.; Daniels, A. D.; Farkas, Ö.; Foresman, J. B.; Ortiz, J. V.; Cioslowski, J.; Fox, D. J.; Gaussian, Inc.: Wallingford, CT, USA, 2009.

(111) Becke, A. D. Phys. Re., Ser. A 1988, 38, 3098-3100.

(112) Becke, A. D. J. Chem. Phys. 1993, 98, 1372-1377.

(113) Becke, A. D. J. Chem. Phys. 1993, 98, 5648-5652.

(114) Stevens, P. J.; Devlin, F. J.; Chablowski, C. F.; Frisch, M. J. J. Phys. Chem. 1994, 98, 11623-11627.

(115) Lee, C. T.; Yang, W. T.; Parr, R. G. Phys. Rev. B 1988, 37, 785-789.

(116) Hay, P. J.; Wadt, W. R. J. Chem. Phys. 1985, 82, 299-310.
(117) Tomasi, J.; Mennucci, B.; Cammi, R. Chem. Rev. 2005, 105, 2999-3093.

(118) Cances, E.; Mennucci, B.; Tomasi, J. J. Chem. Phys. 1997, 107, 3032-3041.

(119) Mennucci, B.; Cances, E.; Tomasi, J. J. Phys. Chem. B 1997, 101, 10506-10517.

(120) Cances, E.; Mennucci, B. J. Math. Chem. 1998, 23, 309326. 


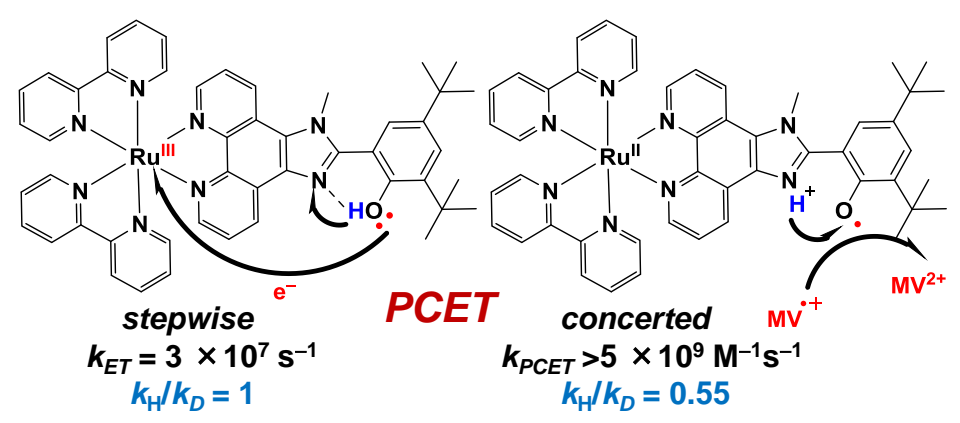

